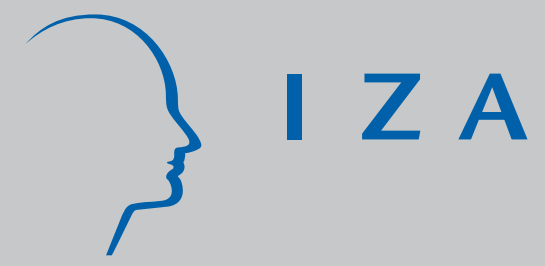

IZA DP No. 4528

Immigration, Citizenship, and the Size of Government

Francesc Ortega

October 2009

Forschungsinstitut zur Zukunft der Arbeit Institute for the Study of Labor 


\title{
Immigration, Citizenship, and the Size of Government
}

\author{
Francesc Ortega \\ Universitat Pompeu Fabra \\ and IZA
}

Discussion Paper No. 4528

October 2009

\author{
IZA \\ P.O. Box 7240 \\ 53072 Bonn \\ Germany \\ Phone: +49-228-3894-0 \\ Fax: +49-228-3894-180 \\ E-mail: iza@iza.org
}

Any opinions expressed here are those of the author(s) and not those of IZA. Research published in this series may include views on policy, but the institute itself takes no institutional policy positions.

The Institute for the Study of Labor (IZA) in Bonn is a local and virtual international research center and a place of communication between science, politics and business. IZA is an independent nonprofit organization supported by Deutsche Post Foundation. The center is associated with the University of Bonn and offers a stimulating research environment through its international network, workshops and conferences, data service, project support, research visits and doctoral program. IZA engages in (i) original and internationally competitive research in all fields of labor economics, (ii) development of policy concepts, and (iii) dissemination of research results and concepts to the interested public.

IZA Discussion Papers often represent preliminary work and are circulated to encourage discussion. Citation of such a paper should account for its provisional character. A revised version may be available directly from the author. 


\section{ABSTRACT}

\section{Immigration, Citizenship, and the Size of Government}

This paper analyzes the political sustainability of the welfare state in an environment where immigration is the main demographic force and where governments are able to influence the size and skill composition of immigration flows. Specifically, I present a dynamic politicaleconomy model where both income redistribution and immigration policy are chosen by majority vote. Voters take into account their children's prospects of economic mobility and the future political consequences of today's policies. Over time, the skill distribution evolves due to intergenerational skill upgrading and immigration. I consider three immigration and citizenship regimes. In the first, immigrants stay permanently in the country and citizenship is obtained by birthplace (jus soli). In the second regime immigration is also permanent but citizenship is passed only by bloodline (jus sanguinis). In the third regime immigrants are only admitted temporarily and cannot vote. Our main finding is that under permanent migration and jus soli there exist equilibria where income redistribution is sustained indefinitely, despite constant skill upgrading in the population. However, this is not the case in the other two regimes. The crucial insight is that unskilled voters trade off the lower wages from larger unskilled immigration with the increased political support for redistributive transfers provided by the children of the current immigrants. In contrast, in the regimes where immigrants and their children do not gain the right to vote, unskilled voters oppose any unskilled immigration and political support for income transfers vanishes. We argue that these mechanisms have important implications for the ongoing debates over comprehensive immigration reform in the US and elsewhere.

JEL Classification: F22, I2, J62

Keywords: immigration, citizenship, redistributive policies, political economy

Corresponding author:

Francesc Ortega

Department of Economics and Business

Universitat Pompeu Fabra

Ramon Trias Fargas, 25-27

Barcelona, 08005

Spain

E-mail: francesc.ortega@upf.edu 


\section{Introduction}

"Many immigrants tend to be fairly apolitical, are often slow to naturalize, and are more concerned with problems of day-to-day survival and their children's chances of upward mobility than with engagement in American politics. ${ }^{1}$ Nonetheless, I suggest that the children and grandchildren of the immigrants who arrived during the age of migration from 1880 to 1924 played a major, if not a decisive, role in twentieth-century American politics. In particular, I suggest that their influence tipped the political balance that led to the creation of the modern welfare state in the 1930s..." Charles Hirschman (2001).

Twentieth century US history suggests that immigration played a crucial role in the politics leading to the creation of the modern welfare state. The goal of this paper is to explore the role that immigration will have on the future of the welfare state. More specifically, we investigate the political economy of income redistribution in an environment where immigration is the main source of population growth. In each period, voters choose immigration and redistribution policies by majority vote. Crucially, voters preferences over current policies are influenced by their own skills, their children's expected skill levels, and by the anticipated effects of immigration on future domestic politics.

Let us briefly comment on the main features of this environment. Immigration is the main demographic force and the government is supposed to have the ability to control its size and skill composition. In most rich countries natural population growth nowadays is low (or negative) and overall population growth is mostly driven by immigration. In this context, the fiscal and political implications of immigration are a very important policy issue. Obviously, governments ability to control immigration flows is far from perfect. However, there is clear evidence that changes in immigration policy have profound effects on immigration flows. ${ }^{2}$ Another important feature of our environment is that voters' political views depend not only on their own current economic situation but also on prospects of upward economic mobility. This is in line with the recent literature on the political economy of redistribution (Benabou and Ok 2001, Alesina and La Ferrara 2004). In our setup voters are foresighted and forecast the effects of current immigration policy on political outcomes in the future.

The quotation above highlights the major role of second-generation immigrants in some of the crucial US presidential elections over the past century. Clearly, this would not have been the case had the children of immigrants not been able to obtain US citizenship and, consequently, the right to vote. This highlights the crucial role of the institution of jus soli, by which children born in a country automatically become citizens. In contrast, in jus sanguinis countries citizenship is passed only by bloodline. ${ }^{3}$ Our model analyzes how voters' views are shaped by i) whether immigrants are

\footnotetext{
${ }^{1}$ Portes and Rumbaut 1996: chap 4; Ramakrishnan and Espenshade 2001

${ }^{2}$ The characteristics of US and Canada immigrants over the last decade differ substantially. There is wide consensus that it is due to differences in the immigration policies of the two countries (Borjas, 1999). Ortega and Peri (2009) show that immigration policy changes have large effects on the size of immigration flows for a large sample of OECD countries.

${ }^{3}$ This is the case in Japan and was the case in Germany until 1999. See Bertocchi and Strozzi (2010) for an excellent review of citizenship laws and an analysis of its evolution over time.
} 
allowed to stay in the country permanently or not, and ii) by whether their children are granted citizenship in the host country or not. We compare the outcomes across immigration regimes, hoping to shed light on the recent debates over immigration policy. ${ }^{4}$

The paper contains three main results. First, we show that the optimal policy entails admitting skilled immigrants (to maximize income per capita) and redistributing income vigorously from rich to poor. Second, we show the existence of a majority vote equilibrium with long-run redistribution when immigrants stay permanently in the country and their children gain the right to vote (jus soli). In the steady state, there is an unskilled majority that implements income redistribution. In order to regenerate political support for redistribution the unskilled majority uses immigration policy strategically, admitting a limited number of unskilled immigrants at each period. In contrast, when immigrants do not vote, either because of a limited stay or due to legal constraints, there is no equilibrium where redistribution can be sustained in steady state. Finally, we show that income redistribution is not politically sustainable when immigrants do not vote.

The key insight of the model is that when immigration is permanent and citizenship is granted by jus soli, voters face an inter-temporal trade-off. Unskilled (poor) voters are in favor of unskilled immigration because it increases the political support for redistribution in the future. But this comes at the cost of lower current unskilled wages. As a result, the unskilled majority admits only the unskilled immigration needed to offset the rising share of skilled voters in the economy. However, when immigrants do not vote, either because their stay is temporary or because of jus sanguinis, the trade-off disappears and unskilled majorities choose to admit only skilled immigrants. Eventually, the dynamics of the skill distribution lead to a skilled majority that abandons redistribution.

The strategic use of immigration policy featured in the equilibrium helps explain a puzzling observation. Over the last decade, the Democratic party in the US and left-wing parties in several European countries (such as France, Italy, Spain and the UK) have been substantially more proimmigration than the parties on the right side of the political spectrum. Perhaps even more puzzling is the pro-immigration stance that labor unions have taken in these countries, supporting the right of immigrants to become citizens and to vote. The following quotation nicely illustrates this point in the US context. "Organized labor is looking to Mexico to advance its call for amnesty for the more than five million illegal immigrants, a position that the A.F.L.-C.I.O. adopted last year after decades of hostility to illegal immigrants. But unions are now reaching out to immigrants, seeing them as a source of growth and energy, rather than a threat (New York Times, July 19, 2001)." In the light of the key trade-off in our model, these observations can be easily accounted for.

Our paper is closely related to four strands of literature. First, our work contributes to the literature studying the dynamics of government. Within this body of research, our paper is most related to the recent dynamic political economy models. The approach in Krusell, Quadrini and Rios-Rull (1997) and Krusell and Rios-Rull (1999) requires heavy use of numerical methods and has a quantitative focus. The model I present is more in line with Hassler et al $(2002,2005)$, who employ more stylized models that can be solved analytically. Demographics (and immigration in

\footnotetext{
${ }^{4}$ Offering a track to citizenship for immigrants and their children is a highly controversial issue in the current political debate over comprehensive immigration policy reform in the US. The decade-long discussion has been stalked due to sharp political disagreement on whether a track to permanent residence, ultimately leading to citizenship, should be offered. While most Democrats support it, a large fraction of the Republican party fiercely opposes it.
} 
particular) are absent in these studies. Hassler et al (2002) find that there are multiple equilibria when policies are adopted by majority vote. Positive steady-state redistribution takes place in some equilibria but not in others. Another set of papers studies the effect of exogenous immigration flows on the evolution of the public sector. The papers here have a strong quantitative emphasis. Storeslestten (2000) takes fiscal policies as given and quantifies the effects of immigration on US public finances using a dynamic, general equilibrium model. Canova and Ravn (2000) analyze the effects of German unification in a dynamic model where redistributive transfers are a deterministic function of immigration flows.

Secondly, our work is also related to the literature on the political economy of redistribution, pioneered by Metzler and Richard (1981). Recently, several authors have developed models linking immigration and income redistribution. Typically, these are static models where redistribution is endogenously determined and immigration is taken as exogenous, as in Razin, Sadka and Swagel (2002). Roemer and Van der Straeten (2006) study the consequences of the rise in xenophobia (in Denmark) on the size of the welfare state. The analysis in Dolmas and Huffman (2004) features both endogenous immigration and redistribution policies. These authors propose a three-period model. In the first period, a capital-heterogeneous native population makes consumption-saving decisions and votes over immigration policy. In the second period, the native population and the enfranchised immigrants make saving decisions and vote over next period's degree of income redistribution. In the third period, all individuals simply consume their respective after-redistribution incomes. One obvious difference is that prospects of upward economic mobility play a central role in shaping individual policy preferences in our model but are absent in their analysis. More substantively, the two models differ in several predictions. First, in Dolmas and Huffman (2004) admitting poor immigrants that can vote does not necessarily imply higher redistribution. In fact, under some conditions, it may even lead to a lower tax rate. ${ }^{5}$ In contrast, in our model, an increase in the number of unskilled immigrants with the right to vote unambiguously increases political support for redistribution. The key difference between the two models is the degree of individual heterogeneity in wealth levels. In our highly stylized model there are only two types of voters and each type has a unique preferred tax rate. Second, under perfect capital mobility immigration has no effects on factor prices in Dolmas and Huffman (2004), where only one type of labor is considered. In contrast, we assume that skilled and unskilled labor are not perfect substitutes. As a result, immigration flows that affect the economy's skill composition will induce persistent changes in the skill premium. Finally, the model developed in Dolmas and Huffman (2004) predicts that when immigrants are not allowed to vote, support for increasing immigration levels rises. In a sense, our model delivers the opposite prediction. In our main equilibrium (under permanent immigration and jus soli), there are binding quotas on unskilled immigration. In contrast, when immigrants do not vote, immigration policy in steady state entails larger unskilled inflows, only restricted by the availability of potential immigrants.

Third, our work is also related to the recent literature on the political economy of immigration. This literature was pioneered by Benhabib (1996), who builds a static model where agents with heterogeneous capital holdings choose immigration policy by majority vote. His model abstracts from income redistribution. Ortega (2005) provides an infinite-horizon extension of Benhabib (1996),

\footnotetext{
${ }^{5}$ For a similar result, see Razin, Sadka and Swagel (2002).
} 
where he shows that a stationary equilibrium exists and argues that it accounts better for the recent US immigration experience. The model we introduce here extends Ortega (2005) in several directions. First and foremost, voters choose the degree of income redistribution in addition to immigration policy. Redistributive taxation fundamentally alters the link between immigration flows and individual consumption, which changes voters' views on immigration policy. Introducing redistribution also helps explain why immigration is such a politically salient topic even though the empirical literature strongly suggests that immigration has practically no effect on wages. ${ }^{6}$ Finally, the dynamics in the model we present are much richer than in Ortega (2005).

Finally, our paper is also related to club theory and to the literature on the extension of citizenship and franchise. Conceptually, choosing an immigration policy is akin to deciding on admission to a club. Roberts (2007) and Barbera, Maschler and Shalev (2001) study dynamic games where current club members vote over new membership. In their analysis voters' preferences are exogenously defined over the composition of the club. Our model is much simpler in many respects but features general equilibrium effects on wages. Interestingly, Barbera, Maschler and Shalev (2001) find that some voters sometimes engage in a strategic use of admission policy, admitting individuals that reduce their current payoff in anticipation that the new comers will provide support for desirable policies in the future. They refer to this behavior as "voting for your enemy". Another important contribution to this literature is Jehiel and Scotchmer (2001). These authors build a static model with multiple locations and heterogeneous individuals in their taste for public goods. The timing of choices is sequential, with individuals in each location collectively deciding on admission (immigration policy), taking into account that all individuals in a location will vote over the public good. The fundamental trade-off in the model is the following. Immigrants reduce the per-capita cost of the public good but potentially change the identity of the median voter that will decide on the size of the public good. The authors consider several constitutional arrangements regarding the collective admission of immigrants, ranging from free migration to admission by majority vote or by unanimity. An interesting empirical counterpart to the papers above is Bertocchi and Strozzi (2010). These authors assemble a large, comprehensive cross-country panel of citizenship laws. They estimate the determinants of whether a country grants citizenship based on bloodline (jus sanguinis), on birth place (jus soli), or has a mixed regime. Their findings suggest strong persistence in citizenship laws over time. Finally, choosing admission into a club has similar political economy implications as deciding on franchise extension. Important contributions to this question are Acemoglu and Robinson (2000) and Lizzeri and Persico (2003). More recently, Jack and Lagunoff (2005) explore franchise extension in a dynamic environment.

The plan of the paper is the following. Section 2 presents the model. Section 3 characterizes the optimal policy. Section 4 turns to political (voting) equilibria under permanent migration when citizenship is passed according to jus soli. Section 5 analyzes the two immigration regimes where immigrants do not vote. Section 6 discusses some of the main assumptions and sketches a number of extensions. Figures and proofs are located in the appendix.

\footnotetext{
${ }^{6}$ See, for instance, Card $(2001,2005)$ and Lewis $(2003)$.
} 


\section{Model}

Consider an economy where one final good is produced by a competitive firm using two complementary inputs: skilled and unskilled labor. Let $F\left(L_{1}, L_{2}\right)$ be the production function, a continuous, smooth and constant-returns-to-scale function satisfying the following standard properties: $F_{i}>0$, $F_{i i}<0$ for $i=1,2$ and $F_{12}>0 .{ }^{7}$ Let us define the skilled-unskilled ratio by $k=L_{2} / L_{1}$. It is straightforward to check that $F_{1}(1, k)$ is a strictly increasing function of $k$ and $F_{2}(1, k)$ is a strictly decreasing function of $k$. The respective derivatives (with respect to $k$ ) are $F_{12}>0$ and $F_{22}<0$. To save on notation I will use $F_{i}(k)$ to denote $F_{i}(1, k)$, for $i=1,2$.

The economy is populated by many agents, with one of either two skill levels. Unskilled agents will be denoted by $i=1$ and skilled agents by $i=2$. These workers can be either natives (born in the country) or immigrants (foreign-born). All agents supply one unit of labor inelastically and evaluate consumption streams according to utility function

$$
E_{t} \sum_{j=0}^{\infty} \beta^{j} u\left(c_{t+j}\right),
$$

where $u$ is an increasing, strictly concave, and continuous function. I will interpret these preferences in a dynastic sense. So $c_{t}$ denotes the consumption of a worker at time $t, c_{t+1}$ her only child's consumption and $\beta \in[0,1)$ is the degree of altruism between parents and children. The expectation refers to uncertainty about the skill level of the offspring. We abstract from bequests.

In every period, the government redistributes income from the rich to the poor by means of a proportional income tax $r_{t}$ and a universal transfer $b_{t}$. Thus the individual budget constraint is given by

$$
c_{i t}=\left(1-r_{t}\right) w_{i t}+b_{t},
$$

where $w_{i t}$ is the wage for an individual of skill type $i$ in period $t$. For now, let us assume that taxes are non-distortionary and that feasible tax rates range between 0 and $\bar{r} \leq 1 .{ }^{8}$ We assume that the government runs a balanced budget in each period and that immigrants also pay taxes and receive transfers. ${ }^{9}$

\footnotetext{
${ }^{7}$ It is easy to show that this production function can be interpreted as the reduced-form of a more general function with three inputs (skilled labor, unskilled labor and physical capital), provided the economy faces a perfectly elastic supply of capital. Ortega and Peri (2009) provide empirical evidence supporting that immigration shocks lead to a rapid proportional expansion of the capital stock in the receiving economy. In the absence of capital dilution the only persistent effect of immigration on factors of production is a change in the skill composition of the labor force.

${ }^{8}$ Section 6 shows that $\bar{r}=1$ corresponds to the case of non-distortionary taxation whereas $\bar{r}<1$ is the reduced form of a model where the labor supply of skilled (rich) workers is distorted by taxation.

${ }^{9}$ We are abstracting from intergenerational redistribution. Several authors have analyzed the use of immigration policy as a tool to remedy the forecasted deficits in social security. Available estimates suggest a roughly neutral effect of immigration, once general equilibrium effects are taken into account (Storesletten 2000, Fehr, Jokisch and Kotlikoff 2005). Thus it seems reasonable to leave intergenerational redistribution out of the current analysis.
} 


\subsection{Competitive equilibrium given exogenous policies}

I assume that, given an arbitrary sequence of immigration and redistribution policies, prices and allocations follow a competitive equilibrium. Under the assumptions above, the equilibrium allocation in each period can be written as a function of the period's after-immigration skilled-unskilled ratio $\left(k_{t}\right)$ and income tax rate $\left(r_{t}\right)$. Namely, individual consumption is given by

$$
\begin{aligned}
c_{i}\left(k_{t}, r_{t}\right) & =F_{i}\left(k_{t}\right)+r_{t}\left(f\left(k_{t}\right)-F_{i}\left(k_{t}\right)\right) \\
& =\left(1-r_{t}\right) F_{i}\left(k_{t}\right)+r_{t} f\left(k_{t}\right), \text { for } i=1,2,
\end{aligned}
$$

where $f\left(k_{t}\right)$ denotes output per worker, $Y /\left(L_{1}+L_{2}\right)$, and we have imposed a balanced government budget in each period. It is immediate to show that $f(k)$ is increasing as long as $F_{1}(k)<F_{2}(k)$. Below we shall introduce an assumption that will guarantee that skilled workers will always have a higher marginal product (and thus higher income) than unskilled ones. ${ }^{10}$

Let us now define the indirect utility functions over policies by

$$
v_{i}\left(k_{t}, r_{t}\right)=u\left[c_{i}\left(k_{t}, r_{t}\right)\right], \text { for } i=1,2 .
$$

These functions will be the one-period payoff functions of the dynastic voting model. Obviously, these functions inherit the properties of $c_{i}\left(k_{t}, r_{t}\right)$. In particular, note that $v_{1}\left(k_{t}, r_{t}\right)$ is increasing in $\left(k_{t}\right)$ since it is the sum of two functions that are increasing in the skilled-unskilled ratio. ${ }^{11}$ Note also that when the tax rate is zero $v_{2}\left(k_{t}, r_{t}\right)$ is decreasing in $k_{t}$ since $c_{2 t}=F_{2}\left(k_{t}\right)$.

\subsection{Intergenerational Mobility}

We are interested in economies experiencing human capital accumulation in the form of a growing share of skilled workers. A convenient modelling device is to assume that the skill distribution of the labor force is governed by a two-state Markov chain. That is, children's skills are stochastic but depend on the skills (income level) of their parents. Therefore prospects of economic mobility will influence voters' views on income redistribution (as in Benabou and Ok 2001) and on immigration policy (as in Ortega 2005). ${ }^{12}$

More specifically, let $p_{i}$ be the probability of being skilled given parental skill level $i$. We shall restrict the mobility process in two realistic ways. First, we shall assume intergenerational persistence, so that children are more likely to be of the same type as their parents than not. This is condition (5) below. We shall also assume upward mobility, given by condition (6). That is to say, the probability that an unskilled parent has a skilled child (upgrading) is higher than the

\footnotetext{
${ }^{10}$ Appendix 2 contains some useful properties of function $f(k)$, which are used extensively in the proofs.

${ }^{11}$ Recall that we shall restrict to values of $k_{t}$ such that $F_{1}(k)<F_{2}(k)$.

${ }^{12}$ This is the main reason why we only allow for two skill levels. Existence of a Condorcet winner cannot be guaranteed when more than two types of voters choose among multidimensional policy vectors. Applications where a Condorcet winner can be shown to exist rely on restricted forms of heterogeneity in individual policy preferences. In our setup individual policy preferences are complicated objects since we have altruistic voters with stochastic skill levels (in a dynastic sense).
} 
probability that a skilled parent has an unskilled child (downgrading). ${ }^{13}$ Namely, we assume that

$$
\begin{aligned}
& p_{1}<\frac{1}{2}<p_{2} \\
& p_{1}>1-p_{2} .
\end{aligned}
$$

For the sake of simplicity we also assume that the skills of the children of natives and immigrants are both described by the same Markov chain. ${ }^{14}$ Let us discuss briefly conditions (5) and (6). Imposing intergenerational persistence is a very reasonable assumption, given its strong empirical support. Virtually in all countries, the data show a robust, positive correlation between the educational attainment of parents and children. ${ }^{15}$ The upward mobility condition ensures that the voting problem is non-trivial in all periods. We discuss this point in Section 2.4, where we also show that it can be relaxed. Three more observations are worth noting. First, the two conditions are not mutually exclusive. Second, observe that the case of no mobility (full persistence), $p_{1}=1-p_{2}=0$, is a particular case satisfying both conditions. ${ }^{16}$ Third, realistic parameter values feature both intergenerational persistence and upward mobility. Appendix 1 provides my own estimates based on US individual-level data (General Social Survey). Mobility parameters $p_{1}=0.37$ and $p_{2}=0.83$ are precisely estimated and satisfy both conditions. Moreover, we obtain very similar estimates for the children of natives and for the children of immigrants.

\subsection{Immigration and citizenship regimes}

As in any political economy model, an important ingredient is the institutional background determining who can vote. We shall consider three regimes. ${ }^{17}$ The first regime will be referred to as temporary migration. Here we assume that immigrants arrive in the country to work. At the end of the period they leave and have children only after they have left the country. The next two regimes involve permanent migration: immigrants participate in the labor market and at the end of their working lives have children. According to our second regime, jus soli, the children of immigrants are considered citizens with full rights and obligations, including the right to vote. ${ }^{18}$ In the third regime, jus sanguinis, citizenship is solely acquired by bloodline. Thus, the children of immigrants

\footnotetext{
${ }^{13}$ In a more general environment skill accumulation would be a conscious investment affected by the market returns to education, income tax rates, family background, and so on. The process specified here can be seen as a reduced form that is both analytically convenient and relatively general at the same time. Section 6.2 sketches an extension of the model with endogenous skill investment.

${ }^{14}$ Intergenerational mobility in education varies by ethnicity but, on average, it is very similar to the mobility rates for natives. See Card (2005) and my own estimates in Appendix 1 for estimates based on US data.

${ }^{15}$ The reasons behind this correlation are more debatable, ranging from hereditary transmission of ability, to nurturing differences by education of the parents, or the presence of tight credit constraints in education financing.

${ }^{16}$ Consider the $\left(p_{1}, p_{2}\right)$ in the $[0,1] \times[0,1]$ space. Intergenerational persistence constrains values in the square with corners $(0,0.5),(0.5,0.5),(0,1),(0.5,1)$, that is, the top-left region. Upward mobility defines the region above the diagonal connecting points $(0,1)$ and $(1,0)$. Clearly, the intersection of the two regions is non-empty.

${ }^{17}$ In reality there are many mixed regimes, which combine features of the three canonical regimes considered here. See Bertocchi and Strozzi (2010) for more details.

${ }^{18}$ In the context of our model it is irrelevant if the first-generation immigrants are given the right to vote, since all relevant policies in the period have already been chosen. The quotation in page 1 suggests that the political influence of the second generation is much larger than that of their parents.
} 
stay in the country and work in the next period but do not have the right to vote. From a political economy perspective, regimes one (temporary migration) and three (permanent migration with jus sanguinis) have very similar implications. We shall refer to these two regimes collectively as the case where immigrants do not vote. In one case this is because they have already left the country. In the other it is because of legal constraints.

Let us now describe the laws of motion for the electorate and the labor force in each of the three regimes. Let the current population be denoted by vector

$$
\left(N_{1}(t), N_{2}(t), J_{1}(t), J_{2}(t), I_{1}(t), I_{2}(t)\right),
$$

where, for skill level $i, N_{i}(t)$ denotes native-born individuals with citizenship, $J_{i}(t)$ denotes native-born individuals without citizenship, and $I_{i}(t)$ denotes foreign-born individuals. The numbers of native-born individuals, with or without citizenship, are predetermined variables whereas the number of foreign-born individuals currently in the labor force, $I_{i}(t)$, is an outcome of the current immigration policy. In all three regimes, the labor force is composed of all three groups of individuals. That is,

$$
L_{i}(t)=N_{i}(t)+J_{i}(t)+I_{i}(t) .
$$

In the regimes where immigrants do not vote (temporary migration or permanent migration with jus sanguinis), next period's voters are the children of the current citizens. That is,

$$
\left(\begin{array}{c}
N_{1}(t+1) \\
N_{2}(t+1)
\end{array}\right)=\left(\begin{array}{cc}
1-p_{1} & 1-p_{2} \\
p_{1} & p_{2}
\end{array}\right)\left(\begin{array}{c}
N_{1}(t) \\
N_{2}(t)
\end{array}\right)
$$

In contrast, under permanent migration and jus soli, the skill distribution of voters evolves according to:

$$
\left(\begin{array}{c}
N_{1}(t+1) \\
N_{2}(t+1)
\end{array}\right)=\left(\begin{array}{cc}
1-p_{1} & 1-p_{2} \\
p_{1} & p_{2}
\end{array}\right)\left(\begin{array}{c}
L_{1}(t) \\
L_{2}(t)
\end{array}\right)
$$

where $L_{i}(t)$ denotes the number of individuals in the labor force with skill level $i$. In words, all children born in the country are considered citizens, regardless of the status of the parents. Moreover, in subsequent periods all native-born individuals will be citizens under the jus soli regime. That is, $J_{i}(t+k)=0$ for all $k>0$.

For the remainder it will be very useful to define the skilled to unskilled ratio among the voting population (natives with citizenship) in each period by

$$
n_{t}=\frac{N_{2}(t)}{N_{1}(t)}
$$

Variable $n_{t}$ will be the main state variable in the dynamic voting problem. It is straightforward to show that under the jus soli regime the law of motion for $n_{t}$ can be written solely as a function of the skilled-unskilled ratio in the labor force $\left(k_{t}\right)$ and the mobility parameters:

$$
n_{t+1}=M\left(k_{t} ; p_{1}, p_{2}\right)=\frac{p_{1}+p_{2} k_{t}}{1-p_{1}+k_{t}\left(1-p_{2}\right)} .
$$


Mobility function $M$ maps the skills of the current adult population (the parents) to the skills of the native population with voting rights in the next period (their children). In the regimes where immigrants do not vote the law of motion for $n_{t}$ is simpler: $n_{t+1}=M\left(n_{t} ; p_{1}, p_{2}\right)$. That is, only the children of citizens are citizens. Some properties of mobility function $M$ will be helpful in our analysis. First, we note that under full persistence $\left(p_{1}=1-p_{2}=0\right)$ the mobility function reduces to the identity function. In words, the share of skilled voters next period is equal to the current period's. Secondly, it is straightforward to verify that, as a function of $k, M$ is increasing and strictly concave. ${ }^{19}$ Figure 1a depics mobility function $M$ using the probabilities estimated in Appendix 1.

\subsection{Evolution of skills in autarky}

It is helpful to examine the dynamics of the skill composition in the absence of immigration (autarky). Obviously, in this case, the before and after migration skilled-unskilled ratios coincide: $k_{t}=n_{t}$ at all periods. As a result, law of motion (11) can be written as $n_{t+1}=M\left(n_{t}\right)$. A bit of algebra shows that function $M$ has a unique fixed point, given by

$$
n^{a}=\frac{p_{1}}{1-p_{2}},
$$

which is increasing in $p_{1}$ and $p_{2}$. By definition, at steady state $n^{a}$ the skilled-unskilled flows (downgrading) balance out with the unskilled-skilled flows (upgrading). We also note that the assumption of upward mobility, condition (6), implies that at steady state there is a skilled majority, that is, $n^{a}>1$.

Let us now illustrate the equilibrium transition (in autarky) from an initial condition, $n_{0}$, to the autarky steady state $n^{a}$. Let us assume that at some initial period skilled workers are scarce, that is, $n_{0}$ is close to zero. As illustrated by Figure 1a, transition function $M\left(n_{t}\right)$ is increasing. Thus, period 1's skilled-unskilled ratio is larger than period 0's: $n_{1}=M\left(n_{0}\right)>n_{0}$. Clearly, the sequence of skilled-unskilled ratios along the autarky equilibrium path, $\left\{n_{t}\right\}$, is increasing and converges to steady-state ratio $n^{a}$. Along the path, skill (and income) inequality fall over time. This behavior is appealing because it mimics, in a very simple way, the evolution of the skill distribution in the US and other developed countries in the postwar period. The fraction of skilled (college-graduate) individuals in the population increased monotonically until reaching a plateau in the last decade. Our model takes these reasonably realistic skill dynamics as given and concentrates in the political economy implications.

By virtue of our upward mobility assumption, the initial unskilled majority $n_{0}<1$ eventually switches to a situation where the skilled population becomes the majority. This switch in majority is what renders the dynamic voting problem interesting. If we assumed, instead, $p_{1}<1-p_{2}$, dynamic considerations would play no role in voters' minds. ${ }^{20}$

\footnotetext{
${ }^{19}$ We also note that $M(0)=p_{1} /\left(1-p_{1}\right), M(\infty)=p_{2} /\left(1-p_{2}\right)$, and the inverse function is given by $k_{t}=M^{-1}\left(n_{t+1}\right)=$ $\frac{n_{t+1}\left(1-p_{1}\right)-p_{1}}{p_{2}-n_{t+1}\left(1-p_{2}\right)}$.

${ }^{20}$ As discussed in Appendix 1, our upward mobility assumption is realistic. However, it is easy to relax by adding an additional parameter to the model. Suppose, for instance, that all skilled citizens vote. However, the turnout rate
} 
Figure 1a plots the mobility function in autarky, that is, with $k_{t}=n_{t}$ for all periods $t$. For reasons that will become clear later, Figure $1 \mathrm{~b}$ plots inverse function $k_{t}=M^{-1}\left(n_{t+1}\right)$ under the assumption that the children of immigrants become citizens. Thus we have current after-migration skilled-unskilled ratios $\left(k_{t}\right)$ in the vertical axis and next period's native ratios $\left(n_{t+1}\right)$ in the horizontal axis. Let us now consider a current skilled-unskilled ratio in the labor force below the autarky steady state, say, $k_{t}=1$. Moving horizontally across the Figure, upward mobility implies $n_{t+1}=M(1)>1$, that is, the system transitions from an equal number of skilled and unskilled individuals to a majority of skilled natives in the next period. Finally, it will be useful to define after-migration ratio $\phi$ as the value that leads to a a balanced population in terms of skills in the next period:

$$
M(\phi)=1 .
$$

It follows easily from $(11)$ that $\phi=\left(1-2 p_{1}\right) /\left(2 p_{2}-1\right)$ and $\phi<1$. This ratio will play an important role when policies are determined by majority vote as it entails a tie in the election.

\subsection{The supply of immigrants}

At any point in time, the skill distribution of the voting population is fully characterized by the skilled-to-unskilled ratio $n_{t}$. By choosing immigration policy, we can vary the skill composition of the labor force, $k_{t}$, which determines wages and individual consumption levels. Naturally, our choices are constrained by the availability of potential immigrants.

A convenient way to model the supply of immigrants is the following. Given pre-migration ratio $n_{t}$, the set of feasible after-migration ratios $k_{t}$ will be given by

$$
k_{t} \in[a(n), b(n)]
$$

where functions $a(n), b(n)$ are continuous, increasing, and satisfy $a(n) \leq n \leq b(n)$. Thus, by admitting all available unskilled immigrants (and no skilled ones) current wages would be determined by ratio $k=a(n)$. Conversely, admitting only skilled immigrants would deliver a ratio $b(n)$. Obviously, any intermediate ratio can be attained by admitting appropriate numbers of immigrants of either type. ${ }^{21}$ With this flexible formulation, it is easy to analyze different cases regarding the set of feasible immigration policies. Most countries face an asymmetric supply of immigrants, that is, the availability of unskilled immigrants is much larger than the availability of unskilled ones. In the extreme case where only unskilled immigrants are available the choice set would be given by $[a(n), n]$. To be more specific, consider the set of choices for the US and Canada. Both countries are similar in terms of their ability to attract foreign talent (skilled workers). However, the US shares a border with Mexico. As a result, while both the US and Canada might be considered as having the same $b(n)$ function, it may be more appropriate to assume that function $a(n)$ for the

for unskilled voters is less than one. In this case, even if the number of skilled citizens at any given time is lower than the number of unskilled ones, effectively the decisive voter might still be skilled. As a result, we could have a switch in the political majority despite $n^{a}<1$. Gaps in turnout rates by education are well documented. In the 2008 US presidential election, 70 percent of all young voters (under age 30) had gone to college whereas just 57 percent of young U.S. citizens had attended college (2008 CIRCLE Youth Voting Trends).

${ }^{21}$ In general, several vectors of immigrants $\left(I_{1}, I_{2}\right)$ will deliver a given ratio $k$ given a value for $n$. 
US is below the analogous function for Canada. As we shall see soon, the characteristics of this set are crucial for the determination of equilibrium policies.

Figure 2 plots the supply of immigrants. Consider, for example, state $n=1$. As drawn in the Figure, by choosing the appropriate immigration policy it is feasible to increase the skilled-unskilled ratio a little bit but it is possible to reduce it substantially. We shall say that (current) immigration is unskilled when $n_{t}>k_{t}$, that is when the after-immigration skilled-to-unskilled ratio is lower than the ratio among natives only. Likewise, we shall say that immigration is skilled when $n_{t}<k_{t}$.

\section{Optimal policies}

Prior to introducing political competition, it is helpful to study the case where policies are chosen by a benevolent government. This allows us to illustrate how beliefs about future policies are formed. We consider the policy choices of a government that cares about the dynastic utility of the native population at each point in time. For simplicity, we assume that all children born in the country are treated equally by the government (jus soli). ${ }^{22}$ The social welfare function is a timevarying average over the population, where the weights need to vary because of the changing skill composition of the population. These changes are due both to immigration and to intergenerational mobility. The government lacks commitment and needs to forecast how current choices affect the future skill composition in the population.

Let us first consider the simpler static problem faced by the government. Given native population $\left(N_{1}, N_{2}\right)$, the benevolent government chooses a policy vector $(k, r)$ in order to

$$
\max \left\{\frac{N_{1} v_{1}(k, r)+N_{2} v_{2}(k, r)}{N_{1}+N_{2}}=\frac{v_{1}(k, r)+n v_{2}(k, r)}{1+n}\right\},
$$

where $n=N_{2} / N_{1}, k \in[a(n), b(n)]$ and $r \in[0, \bar{r}]$.

The solution to this problem is a simple one. It entails maximum redistribution and skilled immigration at each state, that is, $\left(k^{*}, r^{*}\right)=(b(n), \bar{r})$. Let us show why this is the case. After some algebra, the partial derivatives of the objective function with respect to $k$ and $r$, respectively, can be written as

$$
\begin{array}{r}
\frac{u^{\prime}\left(c_{1}\right)}{1+n}(1+k) r f^{\prime}(k) \\
\frac{F_{2}(k)-f(k)}{1+n}\left(u^{\prime}\left(c_{1}\right) k-u^{\prime}\left(c_{2}\right) n\right) .
\end{array}
$$

At $\left(k^{*}, r^{*}\right)=(b(n), \bar{r})$ both conditions are strictly positive. However, it is not feasible to increase any of the two variables as we are hitting the constraint. Intuitively, the benevolent government uses immigration policy to attain the highest possible income per capita. Since skilled workers have a higher marginal product than unskilled ones, this implies admitting skilled immigrants only. Next it uses taxes to reduce the gap between the marginal utilities of consumption of the two types of workers. This is done by taxing the rich (skilled) as much as possible.

\footnotetext{
${ }^{22}$ Thus $J_{1}(t)=J_{2}(t)=0$
} 
As we show in the next proposition, the static solution is also the solution to the full-fledged dynamic optimal policy problem. We first need to provide a formal definition of optimal policy. Technically, the main difficulty lies in modelling voters' beliefs about the future consequences of current policies. ${ }^{23}$ Let beliefs about future policies be given by a policy function, that is, a pair of functions $(K, R):[\underline{n}, \bar{n}] \rightarrow R_{+}^{2}$ that maps the skilled-to-unskilled ratio $(n)$ in each period to a pair of policies. Given these beliefs about future policies, at each period the government chooses current policies to maximize the average (dynastic) welfare of the native population. Let the dynastic utility of a worker of skill type $i$ be given by $V_{i}(n)$, for $i=1,2$. And let us define the set of feasible policies by $\Gamma(n)=[a(n), b(n)] \times[0, \bar{r}]$. We can now provide a formal definition of an optimal policy.

Definition 1. An optimal policy is a policy rule $(K, R):[\underline{n}, \bar{n}] \rightarrow R_{+}^{2}$ and associated continuation values $\left(V_{1}, V_{2}\right):[\underline{n}, \bar{n}] \rightarrow R^{2}$ such that

i) Given policy rule $(K, R)$ continuation values $\left(V_{1}, V_{2}\right)$ satisfy

$$
\begin{aligned}
& V_{1}(n)=v_{1}(K(n), R(n))+\beta C_{1}(M K(n)) \\
& V_{2}(n)=v_{2}(K(n), R(n))+\beta C_{2}(M K(n)),
\end{aligned}
$$

for all $n \in[\underline{n}, \bar{n}]$, where

$$
C_{i}(n)=\left(1-p_{i}\right) V_{1}(n)+p_{i} V_{2}(n)
$$

is the expected utility of the child before her skill type has been determined.

ii) Given continuation values $\left(V_{1}, V_{2}\right)$, policy rule $(K, R)$ satisfies

$$
(K(n), R(n)) \in \arg \max _{(k, r) \in \Gamma(n)} \frac{v_{1}(k, r)+\beta C_{1}(M k)+n\left[v_{2}(k, r)+\beta C_{2}(M k)\right]}{1+n} .
$$

The first part of the definition simply states that beliefs about the future are determined by the policy rule and the probability distribution over the skills of the offspring. The second part says that the policies are chosen in each period to maximize the average dynastic utility of the native population in that period.

The following proposition (proved in the appendix) describes the optimal policy. ${ }^{24}$

Proposition 1. The optimal policy entails admitting all available skilled immigrants and maximum redistribution in each state. Specifically, the associated policy rule is $(K(n), R(n))=(b(n), \bar{r})$ for all $n$. Moreover, the economy converges to a steady state $n^{*}=M\left(K\left(n^{*}\right)\right)$. At steady state, there is maximum redistribution.

In a nutshell, it is optimal in every period to admit all skilled applicants to maximize income per capita and then engage in vigorous income redistribution to reduce the gap in marginal utilities of consuption. We note the tension between maintaining heavy income redistribution and an increasing share of skilled workers in the economy. The main purpose of the sections that follow is to determine immigration and income redistribution when these policies are chosen by majority vote.

\footnotetext{
${ }^{23}$ For the remainder of the paper we assume that $F_{2}(\bar{n}) \geq F_{1}(\bar{n})$. That is, skilled workers are always richer than unskilled ones.

${ }^{24}$ As can be seen in the proof, we require the maximum tax rate $(\bar{r})$ to be close to one.
} 


\section{Political equilibrium with permanent migration and jus soli}

We now turn to the more interesting case where policies are determined democratically by foresighted voters. We assume that immigrants and their offspring stay in the country permanently. On arrival immigrants can work but cannot vote. However, their children will be considered citizens with the right to vote (jus soli). This creates a link between current immigration flows and future policies. Altruistic voters that care about their children's welfare need to anticipate the effects of current choices on future domestic politics.

\subsection{Static policy preferences}

It is helpful to begin by analyzing voters' static preferences over immigration and redistribution. Recall that the indirect utility functions defined over current policies are given by $v_{i}\left(k_{t}, r_{t}\right)=$ $u\left[c_{i}\left(k_{t}, r_{t}\right)\right]$ where

$$
c_{i}\left(k_{t}, r_{t}\right)=\left(1-r_{t}\right) F_{i}\left(k_{t}\right)+r_{t} f\left(k_{t}\right), \text { for } i=1,2 .
$$

That is, consumption is a convex combination of the own wage and output per worker, with the weight on the own wage given by the tax rate. Static policy preferences are very intuitive. Unskilled workers support maximum redistribution (since their wage is always lower than output per worker) and skilled immigration (since that increases output per worker). Thus, their static preferred policy pair is $\left(k_{1}, r_{1}\right)=(b(n), \bar{r})$. Conversely, skilled workers' statically preferred policies are $\left(k_{2}, r_{2}\right)=$ $(a(n), 0)$, namely, zero redistribution and unskilled immigration. A trivial dynamic extension of this model, where voters are myopic, would be fully described by these policy preferences, law of motion $n_{t+1}=M\left(k_{t}\right)$, and the rule of majority. That is, at each period the adopted policy pair would be the one preferred by the largest group. ${ }^{25}$

\subsection{Definition of equilibrium}

We now turn to the more complicated case, where voters care about the effect of current policies on the welfare of their offspring, taking into account intergenerational mobility in skills (and income). Formally, the problem is a dynamic game with a state variable that summarizes the skill distribution of the electorate at each point in time. As common in the dynamic political economy literature, I restrict attention to stationary (Markov perfect) voting equilibria, where the state variable is the skilled-to-unskilled ratio in the native population. Voters' beliefs about future policies are given by a time-invariant (policy) function of the state variable. Taking the function as given, each voter is assumed to vote for her preferred policy pair. In each state, the policy proposed by the majority of voters is adopted. In the event of a tie, that is when there is an equal number of voters of each type, I assume that the party that decided policies in the last period can do so again. Formally, define state $n=1^{-}$as the tie where unskilled voters decide current policies. Likewise, let state $n=1^{+}$denote the tie where skilled voters decide current policies. State variable $n_{t}$ determines

\footnotetext{
${ }^{25}$ The myopic voters case is reminiscent of Benhabib (1996), which analyzes a model of immigration policy (without redistribution or mobility in skills). A simple dynamic extension of his model gives rise to immigration policy cycles.
} 
which party is in the majority as well as the set of feasible policies. ${ }^{26}$

So far we have considered state space $[\underline{n}, \bar{n}]$. Some states in this set are relatively trivial, in the sense that next period's majority is independent from the current choice of policies. Recall that we defined earlier $\phi$ as the current after-migration ratio that leads to a tie in next period's vote (equation (13) and Figure 1), that is, $n_{t+1}=M(\phi)=1$. Clearly, when the current state is such that there is an overwhelming unskilled majority among voters, even admitting only high skilled immigrants the majority in the next period will remain unskilled. Specifically, when $n_{t} \leq b^{-1}(\phi)$ then $n_{t+1}=M\left(b\left(n_{t}\right)\right) \leq M(\phi)=1$. Similarly, in states with an overwhelming skilled majority, $n_{t} \geq a^{-1}(\phi)$, there will again be a skilled majority in the next period regardless of the immigration policy currently chosen. For these trivial states I shall assume that parties choose policies according to static considerations: unskilled majorities are assumed to choose $(K(n), R(n))=(b(n), \bar{r})$ and skilled majorities are assumed to choose $(a(n), 0) .{ }^{27}$ In the remainder we need to characterize the equilibrium policy rule for non-trivial states. We define the set of such states by

$$
\Omega=\left(b^{-1}(\phi), a^{-1}(\phi)\right) \subset[\underline{n}, \bar{n}] .
$$

Observe that, by construction, for all states $n \in \Omega$ it is the case that $a(n)<\phi<b(n)$. In words, among current feasible immigration policies some give rise to an unskilled majority in the next period while others give rise to a skilled majority. That is, there are non-trivial political consequences from today's policy choices. Figure 2 illustrates the non-trivial state space.

Let us provide a formal definition of a majority vote equilibrium under permanent immigration and jus soli.

Definition 2. A majority vote equilibrium with permanent migration and jus soli is a policy rule $(K, R): \Omega \rightarrow R_{+}^{2}$ and a pair of value functions $\left(V_{1}, V_{2}\right)$ such that:

i) Given $(K, R)$, continuation values are given by

$$
\begin{aligned}
V_{i}(n) & =v_{i}(K(n), R(n))+\beta\left[\left(1-p_{i}\right) V_{1}(M(K(n)))+p_{i} V_{2}(M(K(n)))\right] \\
& =v_{i}(K(n), R(n))+\beta C_{i}(M(K(n))), \text { for all } n \in \Omega \text { and } i=1,2 .
\end{aligned}
$$

ii) In all unskilled majority states, $n \leq 1^{-}$,

$$
(K(n), R(n)) \in \arg \max _{(k, r) \in \Gamma(n)} v_{1}(k, r)+\beta C_{1}(M(k)),
$$

iii) and in all skilled majority states, $n \geq 1^{+}$,

$$
(K(n), R(n)) \in \arg \max _{(k, r) \in \Gamma(n)} v_{2}(k, r)+\beta C_{2}(M(k)),
$$

\footnotetext{
${ }^{26}$ An alternative to majority vote is probabilistic voting (Lindbeck and Weibull, 1987), which is increasingly used in macroeconomic models with political economy (as in Hassler et al 2005). The reason is that the solution to the probabilistic voting problem can be found by analyzing a relatively simple social planning problem with a utilitarian welfare function. This is also the case here. In our model the equilibrium policy rule under probabilistic voting coincides exactly with the optimal policy studied in Section 3.

${ }^{27}$ This restriction of the state space is without loss of generality as long as we restrict to stationary equilibria with state variable $n_{t}$.
} 
where $\Gamma(n)=[a(n), b(n)] \times[0, \bar{r}]$.

The first point in the definition describes how voters' beliefs about the future are formed in a consistent manner. This is just like in the optimal policy problem of the previous section. The second point states that in states with an unskilled majority, $n \leq 1^{-}$, policies are chosen by unskilled voters, taking into account the consequences of current choices for the utility of their offspring. Analogously, the third point states that skilled voters choose policies in states with a skilled majority. ${ }^{28}$

\subsection{Long-run redistribution}

It is worth recalling that under the assumptions that we made earlier on the intergenerational mobility process, in autarky (that is, in the absence of immigration) the economy converges to a skilled majority. As we saw earlier, a benevolent government would redistribute income in all periods. The purpose of this section is to investigate whether, under the same stochastic process for skills, income redistribution is politically sustainable when policies are chosen by majority vote. We show below that, quite intuitively, a skilled majority will never choose to redistribute income toward the poor. Thus the sustainability of redistributive policies requires an unskilled majority to use immigration policy to stabilize the skill distribution of the voting population at a point where they hold the decision power. Namely, it has to be the case that the consequences of redistribution being terminated are bad enough for unskilled voters so as to induce an unskilled majority to admit unskilled immigrants.

A full characterization of the whole set of equilibria in dynamic games is often difficult. This is also the case here. Thus our strategy will be to provide sufficient conditions for the existence of an equilibrium where redistribution is politically sustainable in steady state. Our first result, proved in the appendix, states that voters' views over redistributive policies coincide with their static preferences.

Lemma 1. In any majority vote equilibrium with permanent migration and jus soli

$$
R(n)=\left\{\begin{array}{l}
\bar{r} \text { if } n \leq 1^{-} \\
0 \text { if } n \geq 1^{+}
\end{array}\right.
$$

Recall that a policy rule $(K, R)$ has a steady state $n^{*}$ if $M\left(K\left(n^{*}\right)\right)=n^{*}$. Clearly, Lemma 1 implies that there can be redistribution in steady state if and only if there is an unskilled majority. Therefore a necessary condition for an equilibrium with long run redistribution is a relatively abundant supply of unskilled immigrants. ${ }^{29}$

\footnotetext{
${ }^{28}$ This definition of a politico-economic equilibrium has been used in numerous recent papers. Krusell, Quadrini and Rios-Rull (1997) and Krusell and Rios-Rull (1999) provide numerical solutions for a richer environment. Hassler et al $(2002,2005)$ and Jack and Lagunoff (2005) have provided analytical solutions for more stylized environments.

${ }^{29}$ Specifically, we shall assume that $a(1) \leq \phi$. In words, we are assuming that when the skilled-unskilled ratio among voters equals one, it is feasible to admit enough unskilled immigrants so that the after-migration skilled-unskilled ratio is equal to $\phi$ or lower.
} 
Consider policy rule $(K, R): \Omega \rightarrow R^{2}$ such that

$$
(K(n), R(n))=\left\{\begin{array}{l}
(\phi, \bar{r}) \text { if } n \leq 1^{-} \\
(\phi, 0) \text { if } n \geq 1^{+}
\end{array} .\right.
$$

In unskilled majority states the policy rule specifies full redistribution and $k=\phi$, the skilled ratio that allows unskilled voters to retain the majority while delivering the highest feasible unskilled consumption. In skilled majority states, the rule specifies no redistribution and again $k=\phi$, which delivers the highest possible skilled consumption while maintaining a skilled majority. Note that this policy rule features two steady states: one with redistribution, $n^{*}=1^{-}$, and one without, $n^{*}=1^{+}$. Given an initial unskilled majority, under the policy rule income redistribution will be sustained indefinitely. ${ }^{30}$ Figures $3 \mathrm{a}$ and $3 \mathrm{~b}$ depict policy rule $K(n)$ and $R(n)$, respectively. Over state space $\Omega, K(n)=\phi$ is constant. We can also see the values of the policy rule for the trivial states. Namely, for $n \leq \Omega$, the unskilled majority admits skilled immigrants, $K(n)=b(n)$, and redistributes income. For $n \geq \Omega$, the skilled majority admits unskilled immigrants, $K(n)=a(n)$, and sets the tax rate to zero. Clearly, regardless of the initial condition the economy eventually enters state space $\Omega$. Turning to Figure $3 \mathrm{~b}$, an unskilled majority chooses maximum redistribution $(R(n)=\bar{r})$ whenever in the majority. Likewise, a skilled majority chooses minimum redistribution $(R(n)=0)$ whenever in office.

The following proposition states that this policy can indeed be a majority vote equilibrium under some restrictions on parameter values. The following two assumptions are sufficient conditions.

Assumption 1: $v_{1}(1, \bar{r})>(1-\beta) v_{1}(b(1), \bar{r})+\beta u\left[F_{1}(1)\right]$.

Assumption 2: $u\left[F_{2}(1)\right]>(1-\beta) u\left[F_{2}(a(1))\right]+\beta v_{2}(1, \bar{r})$.

Assumptions 1 and 2 are easy to verify and, respectively, guarantee that unskilled and skilled voters do not want to deviate from equilibrium policy (20). We shall provide the intuition for these assumptions after stating the proposition.

Proposition 2. Let Assumptions 1 and 2 hold. If intergenerational persistence is high enough for both types of voters, policy rule (20) is a majority vote equilibrium with permanent migration and jus soli. Starting from $n_{0}<1$, income redistribution takes place along the equilibrium path and in steady state. Moreover, in steady state an unskilled majority admits a limited number of unskilled immigrants period after period.

We first describe the equilibrium and discuss its implications. Later on we shall provide the basic intuition for the proof and the assumptions. Notice that in steady state, $n_{t}=1>k_{t}=\phi$. That is, there is unskilled immigration. Thus, starting from an initial unskilled majority, we converge to a steady state where the unskilled majority admits unskilled immigrants. This entails a sacrifice in terms of current consumption in exchange for regenerating the political support for redistributive policies. This behavior is reminiscent of the so-called voting for your enemy behavior

\footnotetext{
${ }^{30}$ For tractability we restrict to to equilibria with simple policy rules. In their analysis of the dynamics of government, Hassler et al $(2002,2005)$ restrict to piece-wise linear policy rules.
} 
in the literature on dynamic club formation (Barbera, Maschler and Shalev, 2001). The proposition provides a rationale for why sometimes left-wing parties support less restrictive immigration policies than more conservative parties.

Let us now sketch the proof, which is fairly constructive. The details can be found in Appendix 3. The first step is to compute the continuation equilibrium values. Given the simple structure of the policy rule, this is a relatively easy task. Importantly, expected continuation value functions $C_{i}(n)$ are step functions with a discontinuity at the tie state. The second step is to check that there are no profitable one-period deviations. Consider the case of an unskilled voter in an unskilled majority state. The conjectured policy rule suggests choosing $(k, r)=(\phi, \bar{r})$. This policy pair clearly dominates any pair with $k<\phi$. In all those cases, next period's majority would still be unskilled. However, lower values of $k$ imply lower current consumption. Among the immigration policies that deliver a skilled majority in the next period, the one that dominates all the rest is $(k, r)=(b(n), \bar{r})$. This is the most tempting deviation as it provides the highest possible current consumption. Assumption 1 ensures that this deviation is not profitable for unskilled voters under full intergenerational persistence. It requires the utility from no redistribution to be low enough, compared to a constant consumption stream under maximum redistribution. Finally, a continuity argument shows that there will not be profitable deviations for high enough persistence. An analogous argument applied to skilled voters in states of skilled majority leads to Assumption 2.

Clearly, Assumptions 1 and 2 require relatively high altruism $(\beta)$ in order to induce voters to choose policies that differ from their static best policies. In fact, when $\beta=0$ both assumptions fail (and when $\beta=1$ both are satisfied). We also note that the characteristics of the supply of immigrants play an important role. In particular, it is easy to check that if there were only unskilled immigrants available $(b(n)=n)$ then Assumption 1 holds for any $\beta>0$. Intuitively, unskilled voters have a very high incentive to retain the majority. In this case the equilibrium we propose will hold for a larger region in the parameter space.

\section{Political equilibrium when immigrants do not vote}

Let us now turn to the two alternative immigration regimes. The first regime, temporary migration, is one where immigrants are forced to leave the country at the end of their working lives (and before their children become citizens). ${ }^{31}$ The second regime is one where immigrants can remain permanently in the country but citizenship is passed only by bloodline (jus sanguinis). The common, crucial feature of both immigration regimes is that voters realize that current choices on immigration policy will not affect the skill distribution of voters in the next period. In the former regime, the children of current immigrants do not vote because they (and their parents) have already left the country. In the latter regime, legal constraints do not allow the children of immigrants to vote. Clearly, under these two regimes voters' decision problems are now much simpler. The earlier trade-off between the labor market effects of immigration and its political consequences has now

\footnotetext{
${ }^{31}$ Several countries have implemented temporary-migration policies. In the past hese programs have often been unsuccessful in inducing return migration. Two notable examples are the Bracero program in the US in the 1950s and Germany's gastarbeiterprogramm in the 1960s and 1970s. Nowadays the US and several other countries are considering re-introducing temporary migration programs.
} 
disappeared.

Let us now define an equilibrium when immigrants do not vote.

Definition 3. A majority vote equilibrium when immigrants do not vote is a policy rule $(K, R)$ : $\Omega \rightarrow R_{+}^{2}$ and a pair of value functions $\left(V_{1}, V_{2}\right)$ such that:

i) Given $(K, R)$, continuation values are given by

$$
\begin{aligned}
V_{i}(n) & =v_{i}(K(n), R(n))+\beta\left[\left(1-p_{i}\right) V_{1}(M(n))+p_{i} V_{2}(M(n))\right] \\
& =v_{i}(K(n), R(n))+\beta C_{i}(M(n)), \text { for all } n \in \Omega \text { and } i=1,2 .
\end{aligned}
$$

ii) In all unskilled majority states, $n \leq 1^{-}$,

$$
(K(n), R(n)) \in \arg \max _{(k, r) \in \Gamma(n)} v_{1}(k, r)+\beta C_{1}(M(n)),
$$

iii) and in all skilled majority states, $n \geq 1^{+}$,

$$
(K(n), R(n)) \in \arg \max _{(k, r) \in \Gamma(n)} v_{2}(k, r)+\beta C_{2}(M(n)),
$$

where $\Gamma(n)=[a(n), b(n)] \times[0, \bar{r}] .^{32}$

The key observation is that when immigrants do not vote the evolution of the skills of the electorate is independent from current policies. Specifically, next period's electorate is given by $n_{t+1}=M\left(n_{t}\right)$, rather than $M\left(k_{t}\right)$, as was the case under permanent migration with jus solis. Now the evolution of the skill composition of the electorate is dictated by the exogenous mobility process:

$$
n_{t+1}=M\left(n_{t}\right)=M^{t}\left(n_{0}\right)
$$

which is not affected by the skill composition of the current the labor force $\left\{k_{t}\right\}$. Consequently, the steady state distribution of voters when immigrants do not vote is given by the autarky steadystate, $n^{a}$. It follows that voters' policy preferences coincide with their static best policy pairs. The following result needs no proof.

Proposition 3. Suppose that $n_{t+1}=M\left(n_{t}\right)$, regardless of $k_{t}$. The unique majority vote equilibrium when immigrants do not vote is given by

$$
(K(n), R(n))=\left\{\begin{array}{l}
(b(n), \bar{r}) \text { if } n \leq 1^{-} \\
(a(n), 0) \text { if } n \geq 1^{+}
\end{array},\right.
$$

which has a single steady state $n^{a}=\frac{p_{1}}{1-p_{2}}>1$. At steady state there is a skilled majority and no redistribution.

\footnotetext{
${ }^{32}$ The set of feasible policies under permanent migration with jus sanguinis cannot be expressed as a function of $n$ only. It requires information on the size and skill composition of the native-born, non-citizen population. Nevertheless the equilibrium policy rule is the same as in the temporary migration regime.
} 
Two remarks are in order. First, we point out that the steady state is the same regardless of whether immigrants do not vote because they only stay temporarily or because citizenship is awarded purely on a jus sanguinis basis. However, the transition dynamics will differ because of differences in the set of feasible skilled-unskilled ratios. Second, we note that the long-run sustainability of redistributive policies when immigrants do not vote is fully determined by the parameters governing intergenerational mobility. Under our assumptions the majority of voters are eventually skilled and redistribution abandoned. ${ }^{33}$ The crucial observation is that for parameters values under which redistribution would be abandoned if immigrants did not vote, there exist equilibria with steady-state redistribution when immigrants stay permanently and their children are granted the right to vote.

\section{Discussion and Extensions}

\subsection{Distortionary taxation}

Throughout the paper we have assumed that taxation is non-distortionary and that feasible tax rates ranged from zero to $\bar{r} \leq 1$. We now provide an extension where taxes distort labor supply and, as a result, an upper bound on the tax rate appears endogenously. ${ }^{34}$ Consider the following small departure from our setup. Let us assume that the utility functions of unskilled and skilled workers are given, respectively, by

$$
\begin{array}{r}
U_{1}(c, l)=u(c) \\
U_{2}(c, l)=u(c)-v(l),
\end{array}
$$

where $(c, l)$ are consumption and labor bundles. Unskilled workers inelastically supply labor (one unit) while skilled workers make a consumption-leisure choice. Function $v(l)$ measures the disutility from work. We assume it is positive, increasing, and strictly convex. In this context, given policies $(k, r)$ the competitive equilibrium allocation for the period is characterized by the following system of equations:

$$
\begin{gathered}
M R S\left(c_{2}, l_{2}\right)=F_{2}\left(l_{2} k\right)(1-r) \\
c_{1}=(1-r) F_{1}\left(l_{2} k\right)+r f\left(l_{2} k\right) \\
c_{2}=(1-r) F_{2}\left(l_{2} k\right)+r f\left(l_{2} k\right) .
\end{gathered}
$$

Under standard regularity conditions, this system has a unique solution for $\left(c_{1}, c_{2}, l_{2}\right)$. We can now define the indirect utility functions defined over current policies as $v_{i}(k, r)=u\left(c_{i}(k, r)\right)$, for skill type $i=1,2$. It is easy to show the following two properties regarding voters' policy preferences.

\footnotetext{
${ }^{33}$ This would not be the case if the upward mobility condition (equation (6)) were not satisfied. As we argued earlier, this is only a sufficient condition and can be relaxed easily. Moreover, Appendix 2 demonstrates that conditions (5) and (6) are realistic.

${ }^{34} \mathrm{An}$ alternative way to introduce distortionary taxation is by assuming that only a share of GDP is available for consumption. The rest is lost due to inefficiencies associated to redistributive taxation. In the political economy literature it is common to assume a quadratic functional form.
} 
First, for any value of $k$, skilled voters' preferred level of redistribution is $r_{2}=0$. Being the rich, skilled workers obviously dislike taxation. Second, for any value of $k$, unskilled voter's preferred tax rate, $r_{1}$ is strictly lower than one. At a tax rate equal to one, skilled workers maximize utility by working zero hours. Assuming both inputs are essential in production this implies zero consumption for unskilled workers. Provided the marginal disutility of work is low enough at $l_{2}=0$, it will be the case that unskilled voters' preferred tax rate will be positive $\left(r_{1}>0\right)$. In conclusion, imposing $\bar{r}=1$ in our main analysis is equivalent to assuming non-distortionary taxation. Assuming $\bar{r}<1$ is the reduced form of a model where taxation is distortionary.

\subsection{Endogenous skills}

This section sketches a simple extension of the model where individuals make investment decisions in skills. We argue that the steady state of the majority voting equilibrium of this extended model coincides with the steady state of the main model.

Let us take as given the sequence of immigration flows and tax rates for all periods. At each period, each individual chooses whether to invest in education by comparing the increase in consumption, $c_{2}-c_{1}$, to the cost of acquiring skills. We assume that the monetary cost of education (tuition) is negligible but it takes effort to graduate (for instance, it requires to study hard). In particular, $\pi$ denotes the disutility of the effort needed to obtain a degree. That is, an individual chooses to invest in skills if and only if

$$
c_{2}-c_{1} \geq \pi
$$

We also assume that the disutility of effort is idiosyncratic, drawn from a probability distribution $\left(P_{i}\right)$ that depends on the skills of the parents. Moreover, we assume that the children of skilled parents tend to have a lower disutility of effort. For example, it is plausible that children with college-educated parents receive more help with their homework from their parents than the children of less educated parents. Formally, we assume that the distribution of the disutility of effort for children of unskilled parents $\left(P_{1}\right)$ first-order stochastically dominates the distribution for children of skilled parents $\left(P_{2}\right)$. Using the expression for equilibrium consumption and aggregating individual decisions, the fraction of individuals with i-type parents that invest in education is given by

$$
p_{i}\left(k_{t}, r_{t}\right)=P_{i}\left(\left(1-r_{t}\right)\left[F_{2}\left(k_{t}\right)-F_{1}\left(k_{t}\right)\right]\right),
$$

for $i=1,2 .{ }^{35}$ Unlike in the main model, here the transition probabilities are not constant but a function of the current period's policies. In particular, the share of individuals with i-type parents that become skilled is a decreasing function of the skilled-unskilled labor-force ratio $\left(k_{t}\right)$ and the tax rate $\left(r_{t}\right)$. The intuition is simple. The skill premium is lower at higher levels of the skilled-unskilled ratio, which reduces the incentive to invest in skills. Similarly, higher tax rates reduce the return to investment in skills. In the limit, if the tax rate equals one, consumption is equal for both skill levels but becoming skilled is costly. Hence, no one invests in education $\left(p_{1}=p_{2}=0\right)$.

Furthermore, we note that the share of children with skilled parents choosing to become educated is larger than the analogous share for children with unskilled parents. That is, $p_{2}\left(k_{t}, r_{t}\right)>$

\footnotetext{
${ }^{35}$ Recall that $c_{i}=(1-r) F_{i}(1, k)+r f(k)$.
} 
$p_{1}\left(k_{t}, r_{t}\right)$ at all values of $\left(k_{t}, r_{t}\right)$ for which there is a skill premium in terms of consumption. This property is related to our intergenerational persistence assumption (equation (5)) but somewhat weaker. It is clear that by assuming that, over the relevant values of $(k, r)$, disutility costs are relatively high for most children of unskilled parents (so that $p_{1}$ is close to zero) and low enough for most children of skilled parents (so that $p_{2}$ is close to one), our assumption of intergenerational persistence will hold. It is easy to show that there exist distributional assumptions for $\left(P_{1}, P_{2}\right)$ such that the upward mobility condition (equation (6)) will also be satisfied. Under these assumptions, the steady state of the extended model coincides with the steady state of the main model. But, clearly, transition dynamics will be richer in the model with endogenous education since the transition probabilities are now endogenously varying over time.

\section{Conclusions}

As noted by Hirschman (2001), immigration played a major role in the creation of the welfare state in the US. The vote of the immigrants that had arrived over the preceding decades and their children was decisive in several elections in the 1930s and for decades to come. The analysis in this paper suggests that political support for redistribution will remain strong in the US and in other high-immigration countries, provided that immigrants and their children can continue to access citizenship (voting rights) within a reasonably short period of time.

Our main findings complement the work by Hassler et al (2002) in their analysis on the future of the welfare state. In their environment skill accumulation is endogenous but the demographic structure is assumed to be time-invariant. Their main result is that there are equilibria with long-run redistribution, although other equilibria with no redistribution exist as well. In this paper we have analyzed a different environment, where immigration-driven demographics play the key role. Our main result also speaks to the persistence of income redistribution arising from political economy forces. Namely, we have shown the existence of equilibria with long-run redistribution provided that immigration is permanent and citizenship determined by the place of birth. Conversely, our analysis suggests that if immigrants do not vote political support for redistribution will erode and may eventually lead to drastic reductions in the size of the welfare state.

Our results also resonate in the public debate over immigration policy. Currently, several countries are considering undertaking profound reforms of their immigration policies. Certainly in the US, one aspect that is particularly contentious is whether to offer immigrants a track to citizenship. While most Democrats support this option, the vast majority of Republicans oppose it. ${ }^{36}$ The analysis in this paper offers an explanation based on the political economy of income redistribution. We have shown that redistribution is only sustainable in the long run if immigrants are allowed to stay permanently and to become enfranchised. In equilibrium, unskilled voters behave strategically by supporting unskilled immigration (up to a point), in order to maintain the required political support to sustain income redistribution.

\footnotetext{
${ }^{36}$ This was the main reason why the Comprehensive Immigration Reform Act of 2007 proposed by senators John McCain and Ted Kennedy failed to come into law, despite the support of President George W. Bush. For more details, see http://en.wikipedia.org for 'Comprehensive Immigration Reform Act of 2007'.
} 
The analysis conducted here also has interesting empirical implications for the growing literature on the determinants of individual attitudes toward immigration that also consider its fiscal consequences (for instance, Dustmann and Preston 2000, and Facchini and Mayda 2007). Namely, individual skill or current income levels are not sufficient to predict voters' views on immigration, unless we control for some country-specific variables. For instance, unskilled voters are likely to have different views over unskilled immigration if their respective countries differ in whether immigrants can obtain the right to vote, or in prospects of upward economic mobility.

One virtue of the framework developed here is its tractability, which allows for a number of interesting extensions. A particularly relevant extension from a public policy perspective is to focus on inter-generational redistribution. Several authors have explored the relationship between immigration and Social Security (Storesletten 2000, Fehr, Jokisch and Kotlikoff 2005). However, these studies take policies as given and do not explore the political economy implications. Another important question that could be investigated building on the model presented here is the analysis of gaps in the political views of natives and immigrants. For instance, one could allow for differences in the economic prospects of the children of natives and the children of immigrants. This gap in opportunities is likely to map into gaps in political views. Understanding the political views of second-generation immigrants is the key political challenge for the next decade in many countries. 


\section{References}

[1] Acemoglu, D., Robinson J., 2000. "Why Did the West Extend the Franchise? Democracy, Inequality, and Growth in Historical Perspective" Quarterly Journal of Economics 115 (4), pp. 1167-1199.

[2] Alesina, A., La Ferrara, E., 2005. "Preferences for redistribution in the land of opportunities." Journal of Public Economics 89 (5-6), pp. 897-931.

[3] Barbera, S., Maschler, M., Shalev, J., 2001. "Voting for voters: A Model of Electoral Evolution." Games and Economic Behavior 37 (1), pp. 40-78.

[4] Benabou, R., Ok, E., 2001. "Social Mobility And The Demand For Redistribution: The Poum Hypothesis," The Quarterly Journal of Economics, MIT Press, vol. 116(2), pages 447-487, May.

[5] Benhabib, J., 1996. "On the Political Economy of Immigration." European Economic Review 40 (9), pp. 1737-1743.

[6] Bertocchi, G., Strozzi, C., 2010. "'The Evolution of Citizenship: Economic and Institutional Determinants". Journal of Law and Economics, forthcoming, 2010.

[7] Borjas, G., 1999. "Heaven's Door: Immigration Policy and the American Economy." Princeton University Press.

[8] Canova, F., Ravn, M., 2000. "The Macroeconomic effects of German unification: real adjustments and the welfare state." Review of Economic Dynamics 3 (3), pp. 423-460.

[9] Card, D., 2001. "Immigrant Inflows, Native Outflows, and the Local labor Market Impacts of Higher Immigration" Journal of Labor Economics, XIX, pp. 22-64.

[10] Card, D., 2005. Is the New Immigration Really So Bad? The Economic Journal 115, pp. 300-323.

[11] Dolmas, J., Huffman, G., 2004. "On the Political Economy of Immigration and Income Redistribution." International Economic Review, 45 (4), pp. 1129-1168.

[12] Dustmann, C., Preston, I., 2000. "Attitudes to ethnic minorities, ethnic context and location decisions." Economic Journal 111 (470), pp. 353-373.

[13] Dustmann, C., Preston, I., 2004. "Is immigration good or bad for the economy? Analysis of attitudinal responses." Research in Labor Economics 24, pp. 3-34.

[14] Facchini, G., Mayda, A., 2007. "Individual attitudes towards immigrants: Welfare-state determinants across countries." Review of Economics and Statistics, October 2007.

[15] Fehr, Hans, Sabine Jokisch and Laurence J. Kotlikoff, 2005. "The Developed World's Demographic Transition - The Roles of Capital Flows, Immigration, and Policy," in: R. Brooks and A. Razin, Social Security Reform - Financial and Political Issues in International Perspective, New York, 11-43.

[16] Hanson, G. H., Scheve, K., Slaughter, M., 2007. "Public finance and individual preferences over globalization strategies." Economics and Politics 19 (1), pp. 1-33. 
[17] Hassler, J., Rodriguez-Mora, J.V., Storesletten, K., Zilibotti, F., 2002. "The Survival of the Welfare State." American Economic Review 93 (1), pp. 87-112.

[18] Hassler, J., Krusell, P., Storesletten, K., Zilibotti, F., 2005. "The Dynamics of Government." Journal of Monetary Economics 52 (7), pp. 1331-1358.

[19] Hirschman, C., 2001. "The educational enrollment of immigrant youth: a test of the segmentedassimilation hypothesis." Demography 38 (3), pp. 317-336.

[20] Jack, W., Lagunoff, R., 2005. "Dynamic Enfranchisement." Journal of Public Economics 90 (4-5), pp. 551-572.

[21] Krusell, P., Quadrini, V., Ríos-Rull, J.V., 1997. "Politico-Economic Equilibrium and Economic Growth." Journal of Economic Dynamics and Control 21 (1), pp. 243-272.

[22] Krusell, P., Ríos-Rull, J.V., 1999. "On the Size of U.S. Government: Political Economy in the Neoclassical Growth Model." American Economic Review 89 (5), pp. 1156-1181.

[23] Lewis, E., 2003. Local, Open Economies Within the US: How Do Industries Respond to Immigration? Federal Reserve Bank of Philadelphia Working Paper 04-01.

[24] Lindbeck, A., Weibull, J.W., 1987. "Balanced-budget redistribution as political equilibrium." Public Choice 52 (3), 273-297.

[25] Lizzeri, A., Persico, N., 2004. "Why Did the Elites Extend the Suffrage? Democracy and the Scope of Government, with an Application to Britain's 'Age of Reform'." Quarterly Journal of Economics 119 (2), pp. 707-765.

[26] Mayda, A., 2006. "Who is against immigration? A cross-country investigation of individual attitudes toward immigrants." Review of Economics and Statistics 88 (3), pp. 510-530.

[27] Metzler, A., Richard, S., 1981. "A Rational Theory of the Size of Government." Journal of Political Economy 89(5), pp. 914927.

[28] Ortega, F., 2005. "Immigration Quotas and Skill Upgrading in the Labor Force." Journal of Public Economics 89 (9-10), pp. 1841-1863.

[29] Ortega, F., Peri, G., 2009. The Causes and Effects of International Labor Mobility: Evidence from OECD Countries 1980-2005. Human Development Research Paper 2009/06. Also NBER working paper 14833.

[30] Ortega, F., Tanaka, R., 2006. "Gender Specialization in Households: An Empirical Analysis." Universitat Pompeu Fabra working paper 1021.

[31] Portes, A. and R. Rumbaut. 1996. Immigrant America: A Portrait. 2nd ed. Berkeley, CA: University of California Press.

[32] Ramakrishnan, S.K. and T.J. Espenshade. 2001. "Immigrant Incorporation and Political Participation in the United States." International Migration Review 35: 870-909.

[33] Razin, A., Sadka, E., Swagel, P., 2002. "Tax Burden and Migration: A political economy theory and evidence. Journal of Public Economics 85 (2), pp. 167-190. 
[34] Roberts, K., 2007. "Condorcet cycles? A model of intertemporal voting." Social Choice and Welfare 29 (3), pp. 383-404.

[35] Roemer, J., Van der Straeten, K., 2006. "The political economy of xenophobia and distribution: The case of Denmark." Scandinavian Journal of Economics 108 (2), pp. 251-277.

[36] Storesletten, K., 2000. "Sustaining Fiscal Policy Through Immigration." Journal of Political Economy 108 (2), pp. 300-323. 


\section{Appendix 1: Intergenerational mobility in the US}

This appendix provides a back-of-the-envelope estimate of the parameters governing intergenerational mobility in the model. I use individual survey data from the General Social Survey for the United States, which contains information about the educational attainment of parents and children for many individuals and many cohorts. Let us define an individual as being skilled if he or she had 14 years of education or more (some college) and let us say that an individual comes from a skilled family if his or her father was skilled. Ortega and Tanaka (2006) analyze changes in the effects of paternal and maternal education on educational attainment. I estimate $p_{i}$ by calculating the fraction of skilled individuals that were born in a family of type $i=1,2$. I find that $\widehat{p}_{1}=0.33$ and $\widehat{p}_{2}=0.78$, with very small standard errors. When the estimation is restricted to the subsample of children with foreign-born parents the results are quite similar: $\widehat{p}_{1}=0.37$ and $\widehat{p}_{2}=0.83$. Note that these estimates satisfy that $p_{1}>1-p_{2}$ and $p_{1}<0.5<p_{2}$.

\section{Appendix 2: Some useful algebra}

Let $Y=F\left(L_{1}, L_{2}\right)$ be a constant returns to scale production function, with standard neoclassical assumptions. Let us now define output per worker as

$$
y=\frac{F\left(L_{1}, L_{2}\right)}{L_{1}+L_{2}} .
$$

Let us also define the skilled-unskilled ratio $k=L_{2} / L_{1}$. By homogeneity of degree zero and some algebra we can show the following properties:

$$
\begin{array}{r}
y=f(k)=\frac{F(1, k)}{1+k} \\
F(1, k)=F_{1}(k)+k F_{2}(k) \\
f(k)-F_{1}(k)=k\left(F_{2}(k)-f(k)\right) \\
f(k)=F\left(\frac{1}{1+k}, \frac{k}{1+k}\right) \\
f^{\prime}(k)=\frac{F_{2}(k)-F_{1}(k)}{(1+k)^{2}} .
\end{array}
$$

These properties are used throughout the proofs. 


\section{Appendix 3: Proofs}

Proof proposition 1. As shown in the main text, there is a unique solution to the static optimal policy problem. It is given by $\left.\left(k^{*}\right), r^{*}\right)=(b(n), \bar{r})$. Indeed, the solution is the same even if the social welfare function uses the after-migration population $\left(L_{1}(t), L_{2}(t)\right)$ as weights.

We now turn to the dynamic problem. Let us conjecture that the policy rule is the static optimal policy, that is, $(K(n), R(n))=(b(n), \bar{r})$. Below we verify this conjecture in three steps.

First of all, we need to compute the continuation values under the conjectured policy rule. Under the policy rule, for type $i=1,2$,

$$
\begin{aligned}
V_{i}(n) & =u\left((1-\bar{r}) F_{i}(b(n))+\bar{r} f(b(n))\right)+\beta C_{i}(M(b(n))) \\
& =v_{i}((b(n), \bar{r}))+\beta C_{i}(M(b(n)))
\end{aligned}
$$

where $c_{i}(k, r)$ is the consumption level for $i$-type workers when the after-migration skilledunskilled ratio is $k$ and the tax rate is $r$.

Using the definition of $C_{i}(n)$ and substituting it forward we obtain

$$
\begin{aligned}
C_{i}(n) & =\left(1-p_{i}\right) V_{1}(n)+p_{i} V_{2}(n) \\
& =\left(1-p_{i}\right) v_{1}(b(n), \bar{r})+p_{i} v_{2}(b(n), \bar{r})+\left(1-p_{i}\right) \beta C_{1}(M(b(n)))+p_{i} \beta C_{2}(M(b(n))) \\
& =\sum_{t=0}^{\infty} \beta^{t}\left[\left(1-p_{i}\right) v_{1}\left(b\left(n_{t}\right), \bar{r}\right)+p_{i} v_{2}\left(b\left(n_{t}\right), \bar{r}\right)\right]
\end{aligned}
$$

where $n_{t}=(M \circ b)^{t}(n)$ is the state in period t, which is obtained by composing t-times function $(M \circ b)(n)=M(b(n))$.

The second step is to provide sufficient conditions for functions $C_{1}(n)$ and $C_{2}(n)$ to be increasing. First, we note that $(M \circ b)^{t}$ is an increasing function, being the composition of increasing functions. Next, let us consider the indirect utility functions defined over current policies:

$$
v_{1}(k, \bar{r})=u\left((1-\bar{r}) F_{1}(b(n))+\bar{r} f(b(n))\right) v_{2}(k, \bar{r})=u\left((1-\bar{r}) F_{2}(b(n))+\bar{r} f(b(n))\right) .
$$

Clearly, function $v_{1}(k, \bar{r})$ is increasing in $k$. This follows from $F_{12}>0$ and the fact that we are restricting to situations where $F_{2}(k)>F_{1}(k)$. Regarding $v_{2}(k, \bar{r})$, it is also immediate to note that it is increasing in $k$ if $\bar{r}=1$. For cases with $\bar{r}<1$, we need to make additional assumptions. A sufficient (but not necessary) condition is

$$
\left.\frac{\partial e_{2}}{\partial k}(k, \bar{r})=(1-\overline{(} r)\right) F_{22}(k)+\bar{r} f^{\prime}(k)>0
$$

for all $k \in[b(\underline{n}), b(\bar{n})] .{ }^{37}$ Henceforth, we assume that this condition holds. It now follows that both $C_{1}(n)$ and $C_{2}(n)$ are increasing functions.

The third step is to check that there are no profitable one-period deviations from the action suggested by the conjectured policy rule. That is, consider the problem of choosing the current policy vector $(k, r) \in \Gamma(n)$ to

$$
\max \left\{\frac{v_{1}(k, r)+n v_{2}(k, r)}{1+n}+\beta \frac{C_{1}(M(k))+n C_{2}(M(k))}{1+n}\right\}
$$

\footnotetext{
${ }^{37}$ Here is a numerical example. Suppose that $F\left(L_{1}, L_{2}\right)=L_{1}^{1 / 2} L_{2}^{1 / 2}$ and $\bar{r}=0.9$. Then $\frac{\partial e_{2}}{\partial k}(k, \bar{r})>0$ for $k \in$ $(0.07,0.70)$.
} 
First, we note that the choice of the tax rate is purely static. Hence, it is clear that it coincides with the static solution, $r^{*}=\bar{r}$. Now we turn to the choice of immigration policy. As we know, the static best policy is $b(n)$, which follows from the first term in the objective function being increasing in $k$ (given the optimal tax rate). We have also established that the second term is increasing in $k$ as well. Therefore it follows that $k^{*}=b(n)$. This verifies the conjecture.

Proof lemma 1. Let $n \leq 1^{-}$and suppose that $\left(k_{1}, r_{1}\right)$ is the utility-maximizing policy pair for an unskilled voter, with $r_{1}<\bar{r}$. Since the continuation value only depends on $k_{1}$, pair $\left(k_{1}, \bar{r}\right)$ is preferred over $\left(k_{1}, r_{1}\right)$ if and only if $v_{1}\left(k_{1}, \bar{r}\right)>v_{1}\left(k_{1}, r_{1}\right)$, that is

$$
(1-\bar{r}) F_{1}\left(k_{1}\right)+\bar{r} f\left(k_{1}\right)>\left(1-r_{1}\right) F_{1}\left(k_{1}\right)+r_{1} f\left(k_{1}\right) .
$$

But $F_{2}\left(k_{1}\right)>F_{1}\left(k_{1}\right)$ implies $f\left(k_{1}\right)>F_{1}\left(k_{1}\right)$. As a result, the inequality holds. Hence, in any equilibrium, $R(n)=\bar{r}$ if $n \leq 1^{-}$. A symmetric argument proves that $R(n)=0$ if $n \geq 1^{+}$.

Proof proposition 2. Let us start by partitioning the state space as follows. Define sets

$$
\begin{aligned}
U & =\left\{n \in \Omega: n \leq 1^{-}\right\} \\
S & =\left\{n \in \Omega: n \geq 1^{+}\right\},
\end{aligned}
$$

respectively, the set of states with an unskilled majority and the set of states with a skilled majority. Observe that $a(1) \leq \phi$ implies that $1 \in \Omega$, that is, the state space includes states with a skilled majority and states with an unskilled majority.

Next, let us compute continuation values along the equilibrium path. Abusing notation, let U denote any state in set $\mathrm{U}$. According to the policy rule,

$$
\begin{gathered}
V_{1}(U)=v_{1}(\phi, \bar{r})+\beta C_{1}(U) \\
V_{2}(U)=v_{2}(\phi, \bar{r})+\beta C_{2}(U) \\
V_{1}(S)=v_{1}(\phi, 0)+\beta C_{1}(S) \\
V_{2}(S)=v_{2}(\phi, 0)+\beta C_{2}(S) .
\end{gathered}
$$

Using definition $C_{i}(n)=\left(1-p_{i}\right) V_{1}(n)+p_{i} V_{2}(n)$, and previous expressions for the value functions we arrive at the following linear system of equations:

$$
\left(\begin{array}{l}
C_{1}(S) \\
C_{2}(S)
\end{array}\right)=\left(\begin{array}{ll}
1-p_{1} & p_{1} \\
1-p_{2} & p_{2}
\end{array}\right)\left(\begin{array}{l}
u\left(F_{1}(\phi)\right)+\beta C_{1}(S) \\
u\left(F_{2}(\phi)\right)+\beta C_{2}(S)
\end{array}\right)
$$

The solution is given by

$$
\begin{aligned}
\left(\begin{array}{c}
C_{1}(S) \\
C_{2}(S)
\end{array}\right)= & \frac{1}{(1-\beta)\left[1-\beta\left(p_{2}-p_{1}\right)\right]} \\
& \left(\begin{array}{cc}
\left(1-p_{1}\right)-\beta\left(p_{2}-p_{1}\right) & p_{1} \\
1-p_{2} & p_{2}-\beta\left(p_{2}-p_{1}\right)
\end{array}\right)\left(\begin{array}{c}
\left(1-p_{1}\right) u\left(F_{1}(\phi)\right)+p_{1} u\left(F_{2}(\phi)\right) \\
\left(1-p_{2}\right) u\left(F_{1}(\phi)\right)+p_{2} u\left(F_{2}(\phi)\right)
\end{array}\right) .
\end{aligned}
$$

Analogously, we can derive the system of equations for expected continuation values in unskilledmajority states. The solution to that system is given by

$$
\begin{aligned}
\left(\begin{array}{l}
C_{1}(U) \\
C_{2}(U)
\end{array}\right)= & \frac{1}{(1-\beta)\left[1-\beta\left(p_{2}-p_{1}\right)\right]} \\
& \left(\begin{array}{cc}
\left(1-p_{1}\right)-\beta\left(p_{2}-p_{1}\right) & p_{1} \\
1-p_{2} & p_{2}-\beta\left(p_{2}-p_{1}\right)
\end{array}\right)\left(\begin{array}{c}
\left(1-p_{1}\right) v_{1}(\phi, \bar{r})+p_{1} v_{2}(\phi, \bar{r}) \\
\left(1-p_{2}\right) v_{1}(\phi, \bar{r})+p_{2} v_{2}(\phi, \bar{r})
\end{array}\right) .
\end{aligned}
$$


Let us now analyze voters' best responses given these continuation values. Let us start with unskilled voters in unskilled-majority states. Knowing that it is always in their interest to choose maximum redistribution, unskilled voters rank current policies according to

$$
W_{1}(k, \bar{r})=v_{1}(k, \bar{r})+\beta C_{1}(M(k)),
$$

where $k \in[a(n), b(n)]$. Now notice that among $k \leq \phi, C_{1}(M k)=C_{1}(U)$ is constant and therefore $\phi$ dominates all other $k \leq \phi$. Similarly, $b(n)$ dominates $k \in(\phi, b(n)]$. Therefore, choosing $\phi$ will be optimal if and only if

$$
v_{1}(b(1), \bar{r})-v_{1}(\phi, \bar{r}) \leq \beta\left[C_{1}(U)-C_{1}(S)\right] .
$$

Substituting in the expressions obtained earlier for $C_{1}(U)$ and $C_{1}(S)$, and imposing full persistence, $\left(p_{1}, p_{2}\right)=(0,1)$, the expression above simplifies to:

$$
v_{1}(1, \bar{r}) \geq(1-\beta) v_{1}(b(1), \bar{r})+\beta u\left[F_{1}(1)\right] .
$$

When this condition holds with strict inequality (assumption 1), continuity in $\left(p_{1}, p_{2}\right)$ implies that unskilled voters will not want to deviate from the prescribed action provided intergenerational persistence is high enough.

We now turn to skilled voters' best responses. In states with a skilled majority, skilled voters rank current policies by means of

$$
W_{2}(k, 0)=u\left(F_{2}(k)\right)+\beta C_{2}(M(k)),
$$

where $k \in[a(n), b(n)]$ and I imposed zero redistribution. Now notice that among $k<\phi$, $C_{2}(M(k))=C_{2}(U)$ is constant and therefore $a(n)$ dominates all other values. Similarly, $\phi$ dominates $k \in[\phi, b(n)]$. Therefore, choosing $\phi$ will be optimal if and only if

$$
u\left(F_{2}(a(1))\right)-u\left(F_{2}(\phi)\right)-\beta\left[C_{2}(S)-C_{2}(U)\right] \leq 0 .
$$

It is straightforward to check that under full persistence, $\left(p_{1}, p_{2}\right)=(0,1)$, condition (49) simplifies to

$$
u\left[F_{2}(1)\right] \geq(1-\beta) u\left[F_{2}(a(1))\right]+\beta v_{2}(1, \bar{r}) .
$$

When this condition holds with strict inequality (assumption 2), expression (49) will also hold for high enough intergenerational persistence. Finally, for high enough intergenerational persistence for both types of workers, the proposed rule will be an equilibrium policy rule.

Proof proposition 4. First, we compute equilibrium continuation values. Given that there is full persistence, it is easy to show that

$$
V_{i}(n)=\left\{\begin{array}{l}
\frac{v_{i}(b(n), \bar{r})+\beta u\left[F_{i}(n)\right]}{1-\beta^{2}} \text { if } n \leq 1^{-} \\
\frac{u\left[F_{i}(a(n)]+\beta v_{i}(n, \bar{r}]\right.}{1-\beta^{2}} \text { if } n \geq 1^{+}
\end{array}\right.
$$

We note that $V_{1}(n)$ may be discontinuous at $n=1$. But it is piece-wise increasing. That is, to the left and to the right of the discontinuity it is increasing.

Second, we need to ensure that there are no profitable one-period deviations for unskilled voters in states with unskilled majority, that is, for $\left\{n \leq 1^{-}\right\}=\left(b^{-1}(1), 1^{-}\right] .{ }^{38}$ Since $V_{1}(n)$ is piece-wise increasing, the most tempting one-period deviation is $(k, r)=(1, \bar{r})$. Such a deviation will not be profitable if and only if

$$
v_{1}(b(n), \bar{r})+\beta V_{1}(b(n)) \geq v_{1}(1, \bar{r})+\beta V_{1}\left(1^{-1}\right) .
$$

\footnotetext{
${ }^{38}$ Recall that $\phi=1$ under full persistence.
} 
at every $n \leq 1^{-}$. Since the left-hand side is increasing in $n$, the condition will hold if and only if it holds at the lowest value of $n$, namely at $n=b^{-1}(1)$. That is, if and only if

$$
V_{1}\left(1^{+} \geq V_{1}\left(1^{-}\right)\right. \text {. }
$$

Substituting in the expressions for the continuation values we obtain that there will be no profitable one-period deviation for unskilled workers in unskilled majority states if and only if

$$
v_{1}(b(1), \bar{r})-u\left[F_{1}(a(1))\right] \geq \beta\left[v_{1}(1, \bar{r})-u\left[F_{1}(1)\right]\right] .
$$

Let us now turn to skilled voters. We need to ensure that there are no profitable one-period deviations from the prescribed rule in skilled majority states. These states are given by $\left\{n \geq 1^{+}\right\}=$ $\left[1^{+}, a^{-1}(1)\right)$. The payoff associated to current choices is given by

$$
W_{2}(k, 0)=u\left[F_{2}(k)\right]+\beta V_{2}(M(k)),
$$

for $k \in[a(n), b(n)]$ where we are making use of the fact that optimal choices always involve a zero tax rate. The continuation values are given by the expressions derived earlier. Unfortunately, function $V_{2}(n)$ is not monotonic. Thus there is no neat analytical characterization of the most tempting one-period deviation. As a result, we cannot derive a simple necessary and sufficient condition as for the case of unskilled voters.

The following is a sufficient (but not necessary condition). Suppose

$$
\max _{k \in\left[a(1), b^{2}(1)\right]}\left\{u\left[F_{2}(k)\right]+\beta V_{2}(k)\right\} \leq \min _{n \in\left[1, a^{-1}\right]}\left\{u\left[F_{2}(a(n))\right]+\beta V_{2}(a(n))\right\} .
$$

Observe that this condition will hold for values of $\beta$ low enough. 


\section{Figures}

Figure 1: Intergenerational mobility

Fig. 1a: Mobility function in Autarky

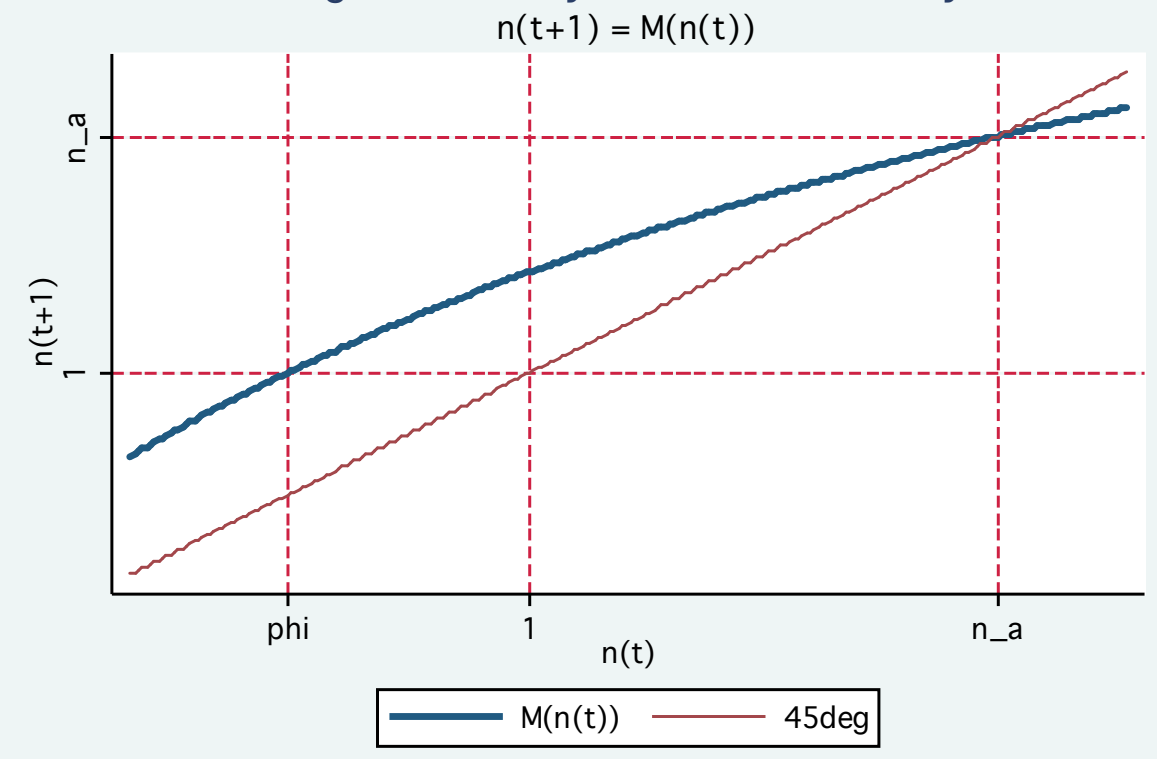

Fig $1 \mathrm{~b}$ : Inverse mobility function

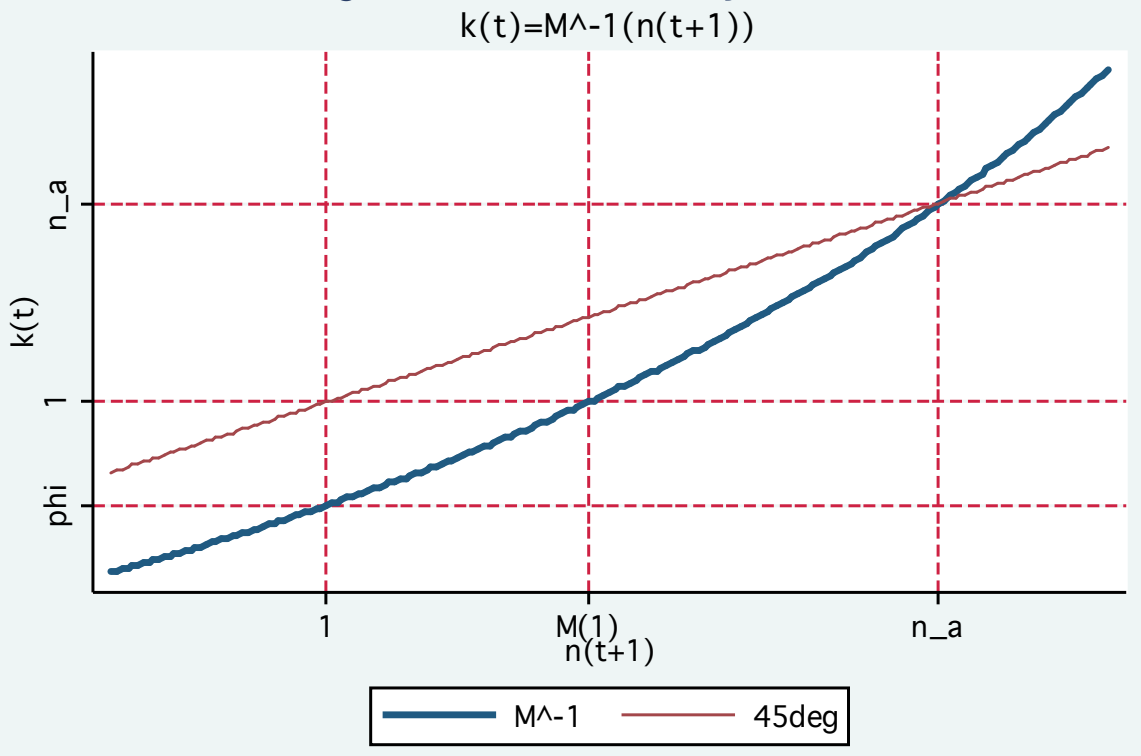


Figure 2: Supply of immigrants

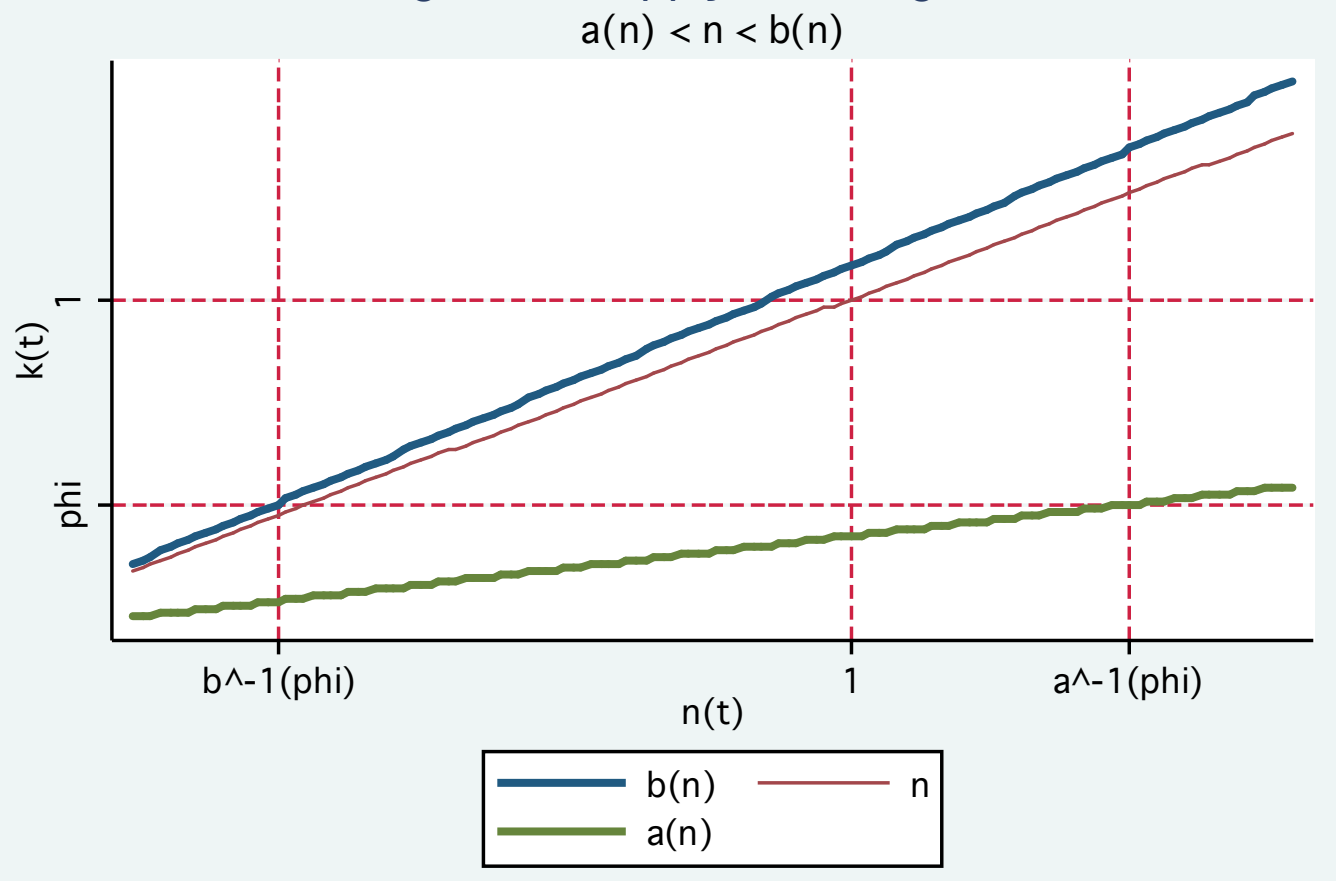


Figure 3: Equilibrium policy rules under permanent migration and jus soli

Figure 3a: Long-run redistribution

Skilled-unskilled policy rule $K(n)$

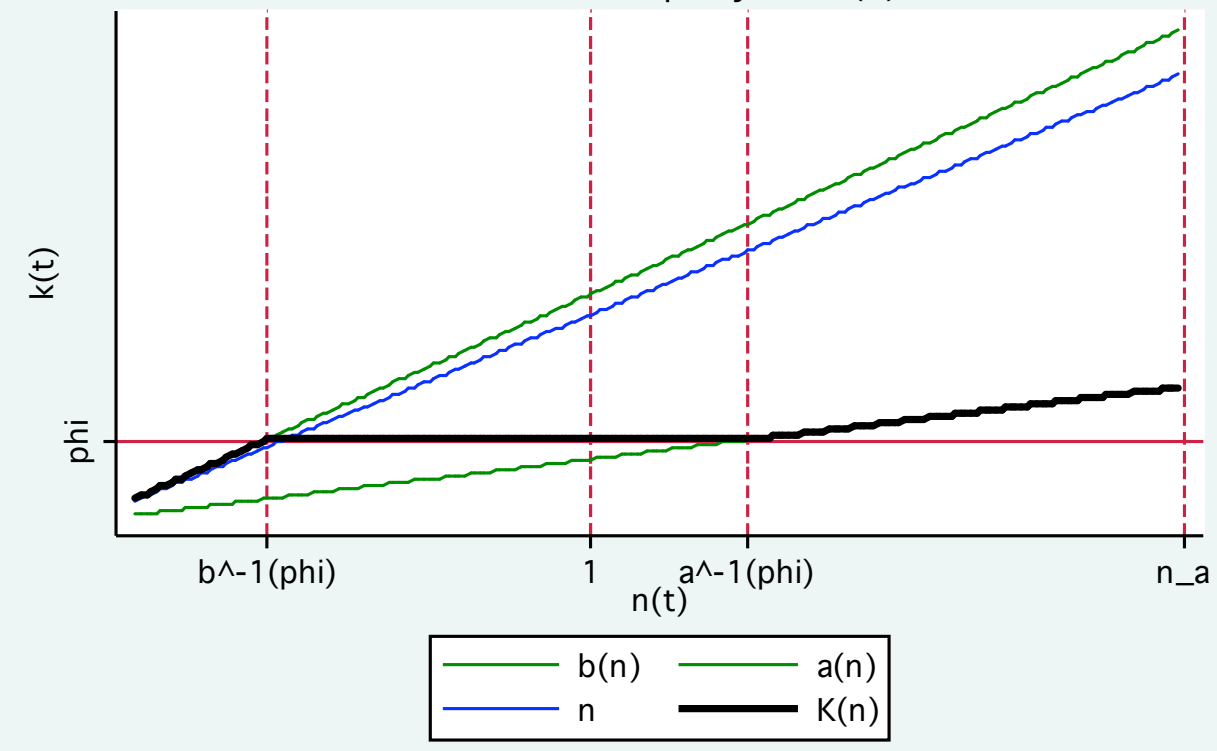

Figure $3 \mathrm{~b}$ : Long-run redistribution

Redistribution policy rule $R(n)$

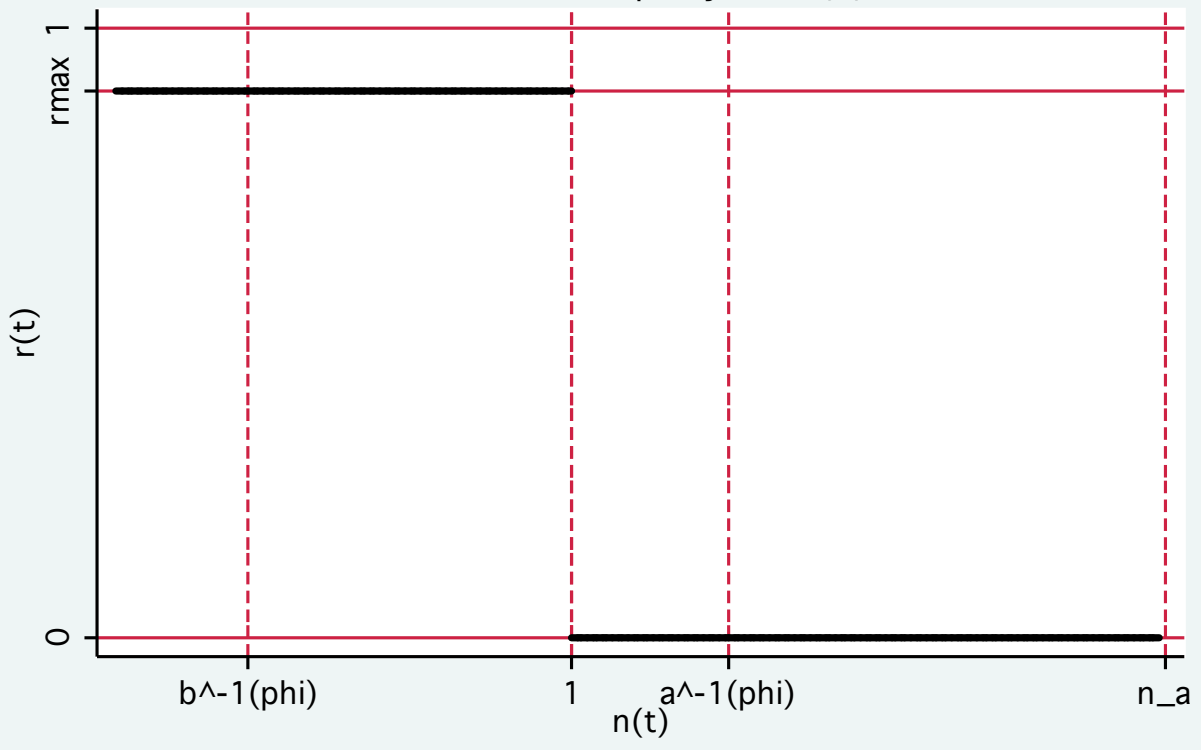

